\title{
Turkish League Against Rheumatism (TLAR) Recommendations for the Pharmacological Management of Rheumatoid Arthritis: 2018 Update Under Guidance of Current Recommendations
}

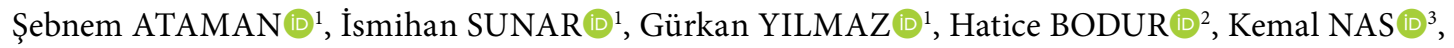

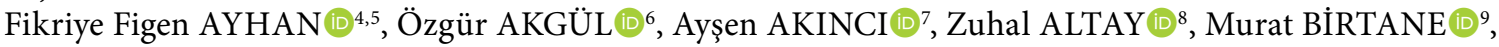 \\ Derya SOY BUĞDAYCI (1) ${ }^{10}$, Erhan ÇAPKIN ${ }^{11}{ }^{11}$, Remzi ÇEVIK (1) ${ }^{12}$, Yeşim GARIP ÇIMEN ${ }^{13}$, \\ M. Tuncay DURUÖZ(1) ${ }^{14}$, Atilla Halil ELHAN (1) ${ }^{15}$, Gülcan GÜRER (10 ${ }^{16}$, Cahit KAÇAR (1) ${ }^{17}$,

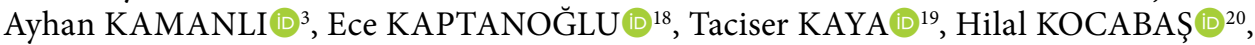

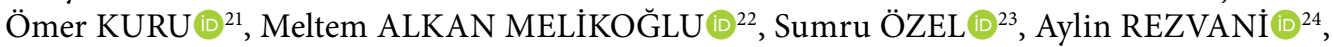 \\ İlhan SEZER (10 ${ }^{25}$, Fatma Gül YURDAKUL(1) ${ }^{13}$
}

\footnotetext{
${ }^{1}$ Department of Physical Medicine and Rehabilitation, Division of Rheumatology, Ankara University School of Medicine, Ankara, Turkey ${ }^{2}$ Department of Physical Medicine and Rehabilitation, Division of Rheumatology, Yildirım Beyazit University School of Medicine, Ankara, Turkey ${ }^{3}$ Department of Physical Medicine and Rehabilitation, Division of Rheumatology, Sakarya University School of Medicine, Sakarya, Turkey

${ }^{4}$ Department of Physical Medicine and Rehabilitation, Uşak University, High School of Health Sciences, Uşak, Turkey

${ }^{5}$ Department of Physical Medicine and Rehabilitation, Division of Rheumatology, Ankara Training and Research Hospital, Ankara, Turkey ${ }^{6}$ Department of Physical Medicine and Rehabilitation, Division of Rheumatology, Celal Bayar University School of Medicine, Manisa, Turkey

${ }^{7}$ Department of Physical Medicine and Rehabilitation, Hacettepe University School of Medicine, Ankara, Turkey

${ }^{8}$ Department of Physical Medicine and Rehabilitation, İnönü University School of Medicine, Malatya, Turkey

${ }^{9}$ Department of Physical Medicine and Rehabilitation, Trakya University School of Medicine, Edirne, Turkey

${ }^{10}$ Department of Physical Medicine and Rehabilitation, İstanbul Training and Research Hospital, İstanbul, Turkey

${ }^{11}$ Department of Physical Medicine and Rehabilitation, Karadeniz Technical University School of Medicine, Trabzon, Turkey

${ }^{12}$ Department of Physical Medicine and Rehabilitation, Dicle University School of Medicine, Diyarbakır, Turkey

${ }^{13}$ Department of Physical Medicine and Rehabilitation, University of Health Sciences, Ankara Numune Training and Research Hospital, Ankara, Turkey

${ }^{14}$ Department of Physical Medicine and Rehabilitation, Division of Rheumatology, Marmara University School of Medicine, Istanbul, Turkey

${ }^{15}$ Department of Biostatistics, Ankara University School of Medicine, Ankara, Turkey

${ }^{16}$ Department of Physical Medicine and Rehabilitation, Division of Rheumatology, Adnan Menderes University School of Medicine, Aydin, Turkey

${ }^{17}$ Department of Physical Medicine and Rehabilitation, Division of Rheumatology, Akdeniz University School of Medicine, Antalya, Turkey

${ }^{18}$ Department of Physical Medicine and Rehabilitation, Division of Rheumatology, Cumhuriyet University School of Medicine, Sivas, Turkey

${ }^{19}$ Department of Physical Medicine and Rehabilitation, University of Health Sciences, İzmir Bozyaka Training and Research Hospital, İzmir, Turkey

${ }^{20}$ Department of Physical Medicine and Rehabilitation, Division of Rheumatology,

Necmettin Erbakan University Meram School of Medicine, Konya, Turkey

${ }^{21}$ Department of Physical Medicine and Rehabilitation, Division of Rheumatology, Ondokuz Mayıs University School of Medicine, Samsun, Turkey

${ }^{22}$ Department of Physical Medicine and Rehabilitation, Division of Rheumatology, Atatürk University School of Medicine, Erzurum, Turkey

${ }^{23}$ Department of Physical Medicine and Rehabilitation, Hitit University School of Medicine, Çorum, Turkey

${ }^{24}$ Department of Physical Medicine and Rehabilitation, Bezmiâlem Foundation University, İstanbul, Turkey

${ }^{25}$ Department of Physical Medicine and Rehabilitation, University of Health Sciences, Antalya Training and Research Hospital, Antalya, Turkey
}

Received: February 24, 2018 Accepted: May 08, 2018 Published online: July 09, 2018

Correspondence: İsmihan Sunar, MD. Ankara Üniversitesi Tıp Fakültesi Fiziksel Tıp ve Rehabilitasyon Anabilim Dalı, Romatoloji Bilim Dalı, 06080 Altındağ, Ankara, Turkey. Tel: +90 312 - 5082038 e-mail: dr.ismihan@gmail.com

Citation:

Ataman Ş, Sunar I, Yılmaz G, Bodur H, Nas K, Ayhan FF, et al. Turkish League Against Rheumatism (TLAR) Recommendations for the Pharmacological Management of Rheumatoid Arthritis: 2018 Update Under Guidance of Current Recommendations. Arch Rheumatol 2018;33(3):251-272. 


\begin{abstract}
Objectives: This study aims to report the assessment of the Turkish League Against Rheumatism (TLAR) expert panel on the compliance and adaptation of the European League Against Rheumatism (EULAR) 2016 recommendations for the management of rheumatoid arthritis (RA) in Turkey.

Patients and methods: The EULAR 2016 recommendations for the treatment of RA were voted by 27 specialists experienced in this field with regard to participation rate for each recommendation and significance of items. Afterwards, each recommendation was brought forward for discussion and any alteration gaining $\geq 70 \%$ approval was accepted. Also, Turkish version of each item was rearranged. Last version of the recommendations was then revoted to determine the level of agreement. Levels of agreement of the two voting rounds were compared with Wilcoxon signed-rank test. In case of significant difference, the item with higher level of agreement was accepted. In case of no difference, the changed item was selected.

Results: Four overarching principles and 12 recommendations were assessed among which three overarching principles and one recommendation were changed. The changed overarching principles emphasized the importance of physical medicine and rehabilitation specialists as well as rheumatologists for the care of RA patients in Turkey. An alteration was made in the eighth recommendation on treatment of active RA patients with unfavorable prognostic indicators after failure of three conventional disease modifying anti-rheumatic drugs. Remaining principles were accepted as the same although some alterations were suggested but could not find adequate support to reach significance.
\end{abstract}

Conclusion: Expert opinion of the TLAR for the treatment of RA was composed for practices in Turkish rheumatology and/or physical medicine and rehabilitation clinics.

Keywords: Disease modifying anti-rheumatic drugs; management; rheumatoid arthritis; treatment recommendations; Turkish League Against Rheumatism.

Considerable advances in diagnosis and management of rheumatoid arthritis (RA) have occurred in the last decades. The management of $\mathrm{RA}$ rests primarily on the use of disease modifying anti-rheumatic drugs (DMARDs) which ameliorate signs, symptoms, pain and functional disability, quality of life, and prevent structural joint damage. DMARDs can be classified in two main categories: synthetic DMARDs (sDMARDs) and biologic DMARDs (bDMARDs). sDMARDs are further divided into two subclasses as conventional synthetic DMARDs (csDMARDs) and targeted synthetic DMARDs (tsDMARDs). csDMARDS which include methotrexate (MTX), leflunomide (LEF), sulphasalazine (SSZ), and hydroxychloroquine (HCQ) have been used in the management of RA for a long time. bDMARDs are classified as bio-original (boDMARDs) and biosimilar (bsDMARDs) DMARDs. boDMARDs include tumor necrosis factor inhibitors (TNFi) (infliximab, etanercept, adalimumab, golimumab, and certolizumab pegol), B-cell depleting agent rituximab, T cell co-stimulation inhibitor abatacept, and interleukin (IL)-6 receptor blocking monoclonal antibody tocilizumab, also another IL-6 receptor inhibitor, sarilumab and IL-6 inhibitors, such as sirukumab or clazakizumab. bsDMARDS are bs-infliximab, bs-rituximab, bs-adalimumab, and bs-etanercept. tsDMARDs which are synthetic inhibitors of Janus kinases (JAKs) include tofacitinib, baricitinib, and filgotinib. ${ }^{1-3}$
The European League Against Rheumatism (EULAR) has published several recommendations regarding management of $\mathrm{RA}$ in order to create a standardized care approach and provide physicians with practical information out of abundant trial results. The first recommendations of the EULAR were published in 2010, and updated in 2013 and 2016. ${ }^{4-6}$ The American College of Rheumatology (ACR) also published a guideline for RA treatment in 2008 and updated these recommendations in 2012 and 2015.-9 Although these recommendations stand at the focus of the management of RA, the requirement of modification of the therapeutic algorithm may arise depending on the geographic location of a country, the characteristics of RA patients including lifestyle, environmental factors, and the operation of the healthcare insurance systems. Therefore, Turkish League Against Rheumatism (TLAR), a scientific member of the EULAR since 1947, developed recommendations for the management of RA in Turkey in 2011 and adapted the EULAR recommendations for the management of RA with synthetic and biological DMARDs into Turkish in 2013. ${ }^{10,11}$ In this study, we aimed to report the assessment of the TLAR expert panel on the compliance and adaptation of the EULAR 2016 recommendations for the management of RA in Turkey. This is the third study to develop TLAR RA treatment recommendations based on EULAR recommendations to be used among Turkish rheumatologists and physical medicine and rehabilitation specialists taking care of RA patients. 


\section{MATERIALS AND METHODS}

The TLAR designated 28 members for the "expert committee" from 23 centers throughout Turkey, who actively took care of RA patients, and informed them via e-mails regarding a meeting to take place on 28 October 2017 in Ankara. Twenty-five members replied favorably while three could not participate in the project. The expert committee comprised of 10 rheumatologists, 15 physical medicine and rehabilitation specialists, and two rheumatology fellows. The rheumatology fellows performed the systematic literature search (SLR) on PubMed, MEDLINE, Cochrane, and Scopus using the key words "rheumatoid arthritis", "treatment", "management", and generic names of drugs used in RA for publications between 2015 and 2017. Meta-analyses, randomized controlled trials, reviews, and current recommendations for management of RA were sent via $e$-mails to members of the expert committee prior to the meeting. In the meeting, two voting rounds were performed. Before the voting, EULAR 2016 recommendations for the management of RA were submitted with a slide presentation. Then, voting for each item of EULAR 2016 RA treatment recommendations with synthetic and biologic DMARDs was performed electronically using keypads. Experts were requested to vote for each item with numbers from 0 to 10 ; 0 reflecting "I totally disagree" and 10 reflecting: "I totally agree." Furthermore, each item was graded according to quality of evidence as; A: Further research is very unlikely to change our confidence in the estimate of effect, B: Further research is likely to have an important impact on our confidence in the estimate of effect and may change the estimate, $\mathrm{C}$ : Further research is very likely to have an important impact on our confidence in the estimate of effect and is likely to change the estimate, D: Any estimate of effect is very uncertain. ${ }^{12}$ The experts were requested to grade the items of EULAR 2016 RA treatment recommendations with synthetic and biologic DMARDs considering their expert opinion aside from the literature data. Following the voting, each item was handled separately and any contributions or proposals for change were questioned. An item was changed and revoted only if at least $70 \%$ of participants requested/ supported the change. Level of agreement
(LoA) was calculated for each item. In case of significant difference between two voting rounds, the item with higher LoA was accepted. In case of no difference, the changed item was selected.

\section{Statistical analysis}

Descriptive data were given as mean \pm standard deviation and median (minimum-maximum). LoA for the changed items in the first and second voting rounds of the TLAR were compared by Wilcoxon signed-rank test. $\mathrm{P}$ values less than 0.05 were considered statistically significant.

\section{RESULTS}

Turkish League Against Rheumatism 2018 recommendations for the management of $\mathrm{RA}$ that are fundamentally based on EULAR 2016 $\mathrm{RA}$ management recommendations investigated the accord to the EULAR recommendations while considering the novel studies and exhibiting national nuances. The nomenclature in EULAR 2016 recommendations for the management of RA was adopted identically. 3,6 The papers committed after the introduction of EULAR 2016 recommendations were taken into consideration to avoid any influence on expert opinions.

The level of agreements of EULAR 2016, the first TLAR voting results reflecting the agreement with the EULAR's, and second TLAR voting results were presented in Figures 1 and 2 . We changed three overarching principles, namely $\mathrm{A}, \mathrm{C}$, and $\mathrm{D}$ on detecting a statistically low agreement to EULAR among our expert committee. Despite not being evaluated as significant, $6^{\text {th }}$ and $12^{\text {th }}$ recommendations gained higher agreement than EULAR's and $8^{\text {th }}$ and $9^{\text {th }}$ recommendations displayed lower agreement in TLAR voting. The $8^{\text {th }}$ item for which a revision was offered by the expert panel attained a statistically significant difference after revision and the revised form was accepted. The remaining overarching principles and recommendations were accepted identically with the EULAR recommendations for the management of RA with sDMARDs and bDMARDs: 2016 Update. ${ }^{6}$ The LoAs in the first and second TLAR voting rounds were given in Table 1 and the TLAR 2018 recommendations 


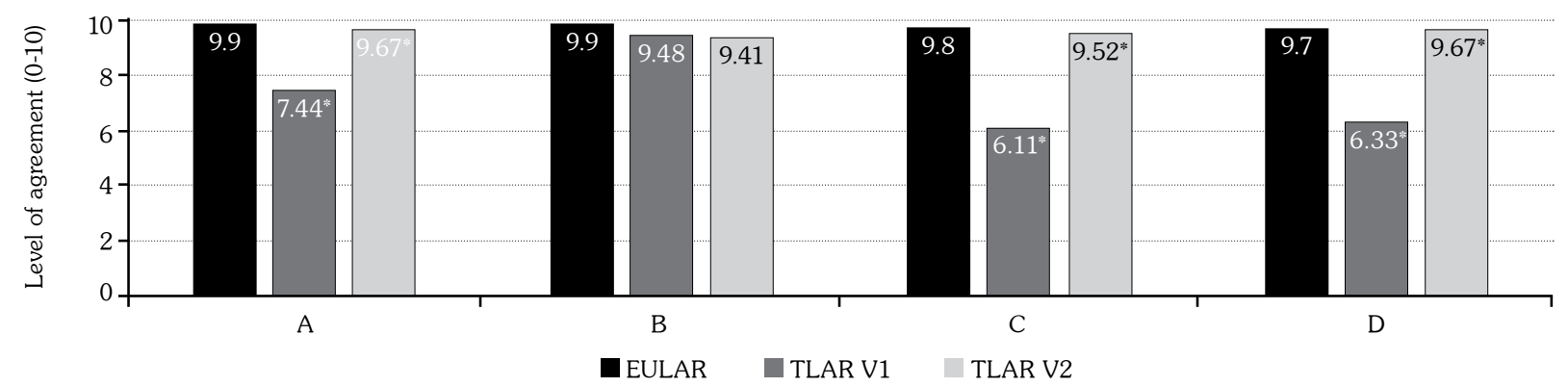

Figure 1. Level of agreements of overarching principles in European League Against Rheumatism, and $1^{\text {st }}$ and $2^{\text {nd }}$ Turkish League Against Rheumatism voting rounds. EULAR: European League Against Rheumatism; TLAR: Turkish League Against Rheumatism. Level of agreements were given as mean; TLAR V1: $1^{\text {st }}$ voting; TLAR V2: $2^{\text {nd }}$ voting; " $p<0.05$ (between TLAR V1 and TLAR V2).

for the management of RA were presented in Table 2.

\section{Overarching Principles:}

A. This principle was changed as "In the management of $R A$ patients, providing the best care should be targeted and the treatment should rely on a co-decision between the physician and the patient."

The term "rheumatologists" in the original form was changed as "physicians." Due to insufficient number of rheumatologists in Turkey, physical medicine and rehabilitation specialists also take care of RA patients. In Turkey, rheumatology subspecialty within the physical medicine and rehabilitation clinics were founded in 1983 for the first time. The Ministry of Health and the Council of Higher Education approved rheumatology subspecialties of both internal medicine and physical medicine and rehabilitation departments since then. As the term "physiatrist" used in TLAR 2013 RA treatment recommendations is commonly misconceived as "physiotherapist", we preferred the term "physical medicine and rehabilitation specialist." However, a more comprehensive phrase; "physician" was chosen in the item since it comprises both these specialties.

Despite not being underlined in the EULAR 2016 recommendations for the management of $\mathrm{RA}$, patient education was also emphasized in the TLAR 2010 consensus recommendations for the management of RA as a separate item: "Patients with RA and their families should be informed and educated, and social support should be provided for the patients. ${ }^{10}$ It has been demonstrated in numerous studies that educational-behavioral programs to protect joints have beneficial effects on pain, disease activity, functional and psychological status in RA. ${ }^{13-15}$ Along with making shared decisions regarding

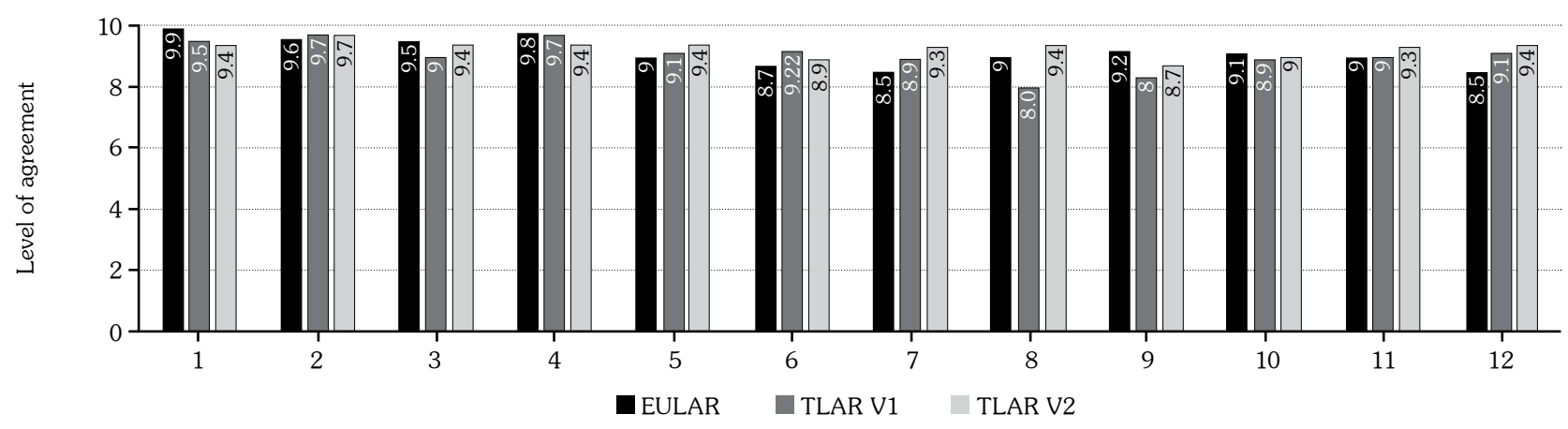

Figure 2. Level of agreements of the 12 recommendations in the European League Against Rheumatism, and $1^{\text {st }}$ and $2^{\text {nd }}$ Turkish League Against Rheumatism voting rounds. EULAR: European League Against Rheumatism; TLAR: Turkish League Against Rheumatism; TLAR V1: $1^{\text {st }}$ voting; TLAR V2: $2^{\text {nd }}$ voting; " $p<0.05$ (between TLAR V1 and TLAR V2). 
the treatment process with the patient, education programs would also contribute to patients' adherence to pharmacological therapy.

The changed item was widely approved. The LoA increased from $7.44 \pm 2.78$ to $9.67 \pm 0.73$ after the revision $(p=0.001)$. The grade of the item is $A$.

B. The item "Treatment decisions should be made considering the disease activity, comorbidities, progression of the structural damage, and safety topics." was accepted the same as the EULAR's.

This item was the $14^{\text {th }}$ recommendation of the 2013 update of the EULAR recommendations for the management of RA with sDMARDS and bDMARDs. In 2016 update, it was considered that this principle should be handled as an overarching principle.
In a recent study to determine the attitude of European rheumatologists to treatment choice, it was noted that drug efficacy was the dominant parameter to affect treatment decisions followed by economic considerations and patients' preferences. ${ }^{16}$

The LoA was $9.48 \pm 1.76$. There was no statistically significant difference between the two voting rounds. The grade of the item is $\mathrm{A}$.

C. The item "Rheumatologists are the specialists who should primarily care for patients with RA." was changed as "Rheumatologists and physical medicine and rehabilitation specialists are the primary experts to take care of RA patients."

As depicted in the 2016 update of the EULAR RA recommendations, the term "primarily" implies that other experienced physicians may follow-up

\begin{tabular}{|c|c|c|c|c|c|c|c|c|c|}
\hline & \multicolumn{2}{|c|}{ Grade } & \multicolumn{6}{|c|}{ LoA } & \multirow{3}{*}{$\begin{array}{c}\text { LoA } \\
\qquad\end{array}$} \\
\hline & \multirow[t]{2}{*}{ (1 $1^{\text {st }}$ voting) } & \multirow[t]{2}{*}{ ( $2^{\text {nd }}$ voting) } & \multicolumn{3}{|c|}{ ( $1^{\text {st }}$ voting $)$} & \multicolumn{3}{|c|}{ ( $2^{\text {nd }}$ voting) } & \\
\hline & & & Mean \pm SD & Median & Min-Max & Mean \pm SD & Median & Min-Max & \\
\hline A & A & A & $7.44 \pm 2.78$ & 9 & $1-10$ & $9.67 \pm 0.73$ & 10 & $7-10$ & 0.001 \\
\hline B & A & A & $9.48 \pm 1.76$ & 10 & $1-10$ & $9.41 \pm 1.78$ & 10 & $1-10$ & 0.623 \\
\hline C & B & A & $6.11 \pm 3.31$ & 6 & $1-10$ & $9.52 \pm 0.89$ & 10 & $7-10$ & $<0.001$ \\
\hline $\mathrm{D}$ & B & A & $6.33 \pm 3.19$ & 6 & $1-10$ & $9.67 \pm 0.62$ & 10 & $8-10$ & $<0.001$ \\
\hline 1 & A & A & $9.52 \pm 1.76$ & 10 & $1-10$ & $9.41 \pm 1.80$ & 10 & $1-10$ & 0.589 \\
\hline 2 & A & A & $9.74 \pm 0.66$ & 10 & $7-10$ & $9.67 \pm 0.68$ & 10 & $8-10$ & 0.589 \\
\hline 3 & A & A & $9.04 \pm 1.89$ & 10 & $1-10$ & $9.41 \pm 0.80$ & 10 & $7-10$ & 0.316 \\
\hline 4 & A & A & $9.67 \pm 0.68$ & 10 & $8-10$ & $9.44 \pm 1.78$ & 10 & $1-10$ & 0.952 \\
\hline 5 & A & A & $9.11 \pm 1.12$ & 9 & $5-10$ & $9.41 \pm 0.75$ & 10 & $8-10$ & 0.265 \\
\hline 6 & A & A & $9.22 \pm 1.01$ & 10 & $7-10$ & $8.93 \pm 1.33$ & 9 & $5-10$ & 0.319 \\
\hline 7 & A & A & $8.85 \pm 1.17$ & 9 & $6-10$ & $9.33 \pm 0.88$ & 10 & $8-10$ & 0.064 \\
\hline 8 & A & A & $8.00 \pm 2.39$ & 9 & $2-10$ & $9.44 \pm 0.93$ & 10 & $7-10$ & 0.002 \\
\hline 9 & B & A & $8.26 \pm 1.63$ & 8 & $3-10$ & $8.74 \pm 1.40$ & 9 & $6-10$ & 0.150 \\
\hline 10 & A & A & $8.93 \pm 1.54$ & 9 & $3-10$ & $9.00 \pm 1.47$ & 10 & $4-10$ & 0.736 \\
\hline 11 & A & A & $8.96 \pm 1.22$ & 9 & $5-10$ & $9.3 \pm 1.14$ & 10 & $5-10$ & 0.344 \\
\hline 12 & A & A & $9.11 \pm 0.93$ & 9 & $6-10$ & $9.44 \pm 0.75$ & 10 & $8-10$ & 0.106 \\
\hline
\end{tabular}

LoA: Level of Agreement; SD: Standard deviation. 
Table 2. Turkish League Against Rheumatism 2018 update recommendations for the pharmacological management of rheumatoid arthritis

\begin{tabular}{|c|c|}
\hline & Overarching principles \\
\hline A & $\begin{array}{l}\text { In the management of RA patients, providing the best care should be targeted and the treatment should rely on a co-decision } \\
\text { between the physician and the patient. }\end{array}$ \\
\hline B & $\begin{array}{l}\text { Treatment decision should be made considering disease activity, comorbidities, progression of the structural damage, and } \\
\text { safety topics. }\end{array}$ \\
\hline C & Rheumatologists and physical medicine and rehabilitation specialists are the primary experts to take care of RA patients \\
\hline \multirow[t]{2}{*}{$\mathrm{D}$} & $\begin{array}{l}\text { RA has high individual, medical, and societal costs. All these aspects should be taken into account by the specialist when } \\
\text { treatment decisions are made. }\end{array}$ \\
\hline & Recommendations \\
\hline 1 & Treatment with DMARDs should be initiated soon after the RA diagnosis is made. \\
\hline 2 & Treatment goal should be achieving sustained remission or low disease activity in all patients. \\
\hline 3 & $\begin{array}{l}\text { In case of active disease, patients should have frequent follow-ups (every one-three months). The treatment should be } \\
\text { re-adjusted if clinical improvement cannot be obtained in three months or the treatment goal cannot be reached within six } \\
\text { months. }\end{array}$ \\
\hline 4 & Methotrexate should constitute a part of the first treatment regimen. \\
\hline 5 & $\begin{array}{l}\text { If MTX cannot be used because of contraindications or intolerance, LEF or SSZ should be started as a part of the first } \\
\text { treatment regimen. }\end{array}$ \\
\hline 6 & $\begin{array}{l}\text { In the periods of csDMARD initiation or change, GCs should be considered for short-term use with different dose and } \\
\text { administration routes; however, it should be tapered rapidly when the clinical condition permits. }\end{array}$ \\
\hline 7 & $\begin{array}{l}\text { If the treatment goal cannot be reached with the first treatment regimen, in the absence of poor prognostic factors, other } \\
\text { csDMARDs should be initiated. }\end{array}$ \\
\hline 8 & $\begin{array}{l}\text { If the treatment goal cannot be reached with the first treatment regimen, in the presence of poor prognostic factors, a } \\
\text { bDMARD or tsDMARD addition should be considered. Generally, bDMARD is the first treatment choice. }\end{array}$ \\
\hline 9 & $\begin{array}{l}\text { bDMARD and tsDMARDs should be used together with a csDMARD. For patients who cannot use csDMARDs along with } \\
\text { these medications, IL- } 6 \text { inhibitors or tsDMARDs may have beneficial effects over other bDMARDs. }\end{array}$ \\
\hline 10 & $\begin{array}{l}\text { In case of bDMARD or tsDMARD failure, treatment with another bDMARD or tsDMARD should be given. In case of one } \\
\text { TNFi failure, another TNFi or medication with a different mechanism may be considered. }\end{array}$ \\
\hline 11 & $\begin{array}{l}\text { In case of persistent remission after tapering GCs in a patient using csDMARDs as comedication, dose reduction of } \\
\text { bDMARDs may be considered. }\end{array}$ \\
\hline 12 & In case of persistent remission after tapering bDMARDs, dose reduction of the csDMARD may be considered. \\
\hline
\end{tabular}

RA patients in the absence of rheumatologists. Additionally, our expert committee emphasized the significance of a multidisciplinary approach including trained healthcare staff such as rheumatology nurses, physiotherapists, and occupational therapists as noted in EULAR 2013 and TLAR 2013 recommendations for RA management. ${ }^{5,11}$

The LoA increased from $6.11 \pm 3.31$ to $9.52 \pm 0.89$ after the revision $(p<0.001)$. The second version was accepted due to significantly increased agreement rate. The grade of the item was B for its original version and became A after the revision.

\section{This item was changed as "RA has high individual, medical, and societal costs. All these aspects should be taken into account by the specialist when treatment decisions are made."}

Considering the incontrovertible role of physical medicine and rehabilitation specialists in the care of RA patients in Turkey, the term "rheumatologist" was altered to a more comprehensive term as "specialist." 
Rheumatoid arthritis has both direct and indirect costs, and the latter is proposed to be higher because of extensive morbidity. Until recently, these costs used to comprise of pharmacological costs including nonsteroidal anti-inflammatory drugs and csDMARDs, rehabilitation measures, issues regarding morbidity, extraarticular problems, and orthopedic surgery. ${ }^{17}$ However, after the introduction of TNFi agents, pharmacological costs are higher and economic issue began drawing more attention. ${ }^{18}$ Also, there are novel studies to evaluate the economic aspects of de-escalation, first-line use, and discontinuation of biologic therapies. ${ }^{19,20}$ According to some authors, early effective treatment with bDMARDs may beneficially contribute to economic burden by postponing disease progression, improving quality of life, decreasing other costs by preserving productivity, and reducing the need for surgery, admission to hospitals, and social service utilization. ${ }^{21}$

The LoA increased from $6.33 \pm 3.19$ to $9.67 \pm 0.62$ after the mentioned change $(p<0.001)$. The second version was accepted due to significantly increased agreement. The grade of the item was $B$ for its original version and became A after the revision.

\section{RECOMMENDATIONS}

\section{1. "Treatment with DMARDs should be initiated soon after the RA diagnosis is made."}

This recommendation remained unchanged since 2010. It emphasizes the importance of establishing early diagnosis. Persistent inflammation leads to erosive joint damage and functional impairment in majority of patients indicating the role of early diagnosis. ${ }^{22,23}$ In this context, our committee underlined the use of ACR-EULAR 2010 classification criteria. ${ }^{24}$ These criteria were developed to rule out some shortcomings of the ACR 1987 criteria, which included features of chronicity and established disease rather than new-onset disease. The new criteria were reported to have $21 \%$ higher sensitivity and $16 \%$ lower specificity than the ACR 1987 criteria. However, it should be borne in mind that classification is not synonymous to diagnosis. ${ }^{25}$ Magnetic resonance imaging (MRI) and ultrasonography also cover an extensive area in research trials and clinical practice of RA. However, future studies are required to optimize the role of MRI and ultrasonography in the diagnosis, monitoring, and economic aspects for the management of RA. ${ }^{26}$

The LoA is 9.52 \pm 1.76 and the grade is A. Since there was no statistically significant difference between the two voting rounds, the item remained unchanged.

\section{2. "Treatment goal should be achieving sustained remission or low disease activity in all patients."}

The term "sustained" was added to the previous version of this item by the EULAR. Although there is no definite evidence regarding the duration of sustained remission, our committee agreed with EULAR's suggestion of at least six months.

Some of the members claimed that low disease activity should not be a target, but may just be an acceptable outcome. However, other members emphasized treat to target recommendations in which the treatment target was defined as clinical remission or at least low-disease activity as the best and second best outcomes in RA. ${ }^{27}$ In a study to evaluate the prognostic differences in RA patients with similar levels of disease activity, it was claimed that low disease activity might be a sufficient treatment goal for anti-cyclic citrullinated peptide antibody (ACPA)-negative patients to prevent progression of joint damage since they have lower probability of damage than ACPA-positive patients. ${ }^{28}$

Our committee also alleged that composite disease activity indices including acute phase reactants may not provide reliable results particularly in patients using agents diminishing the acute phase response, such as IL- 6 inhibitors or JAK inhibitors. Some authors claim that disease activity score 28 (DAS28) might not accurately reflect the remission of RA patients treated with tocilizumab due to its dependence on acute phase response. ${ }^{29}$ Recently, more stringent cut-off points for DAS28-C-reactive protein (CRP) remission have been proposed to surpass overestimation of remission by DAS28 scores. The most recent approach suggests that DAS28-CRP $<1.9$ and DAS28-erythrocyte 
sedimentation rate $(\mathrm{ESR})<2.2$ are related best to clinical disease activity index (CDAI)remission. ${ }^{30}$ However, in a study to test these new cut-points in RA patients on tocilizumab treatment, it was seen that approximately 50\% of patients in DAS28-CRP-remission $(<1.9)$ were in higher disease activity levels according to CDAI and simplified disease activity index (SDAI). Therefore, the authors concluded that even these stringent cut-off values were insufficient to determine the remission reliably due to limitation of score construction of DAS28 itself which frequently harbors residual clinical disease activity even in remission state. ${ }^{31}$

Additionally, nowadays, some composite indices involving the ultrasound findings have been proposed. Moderate to high correlations were reported to exist between the ultrasoundbased disease activity scale UltraSound-CLinical ARthritis Activity (US-CLARA) Index and DAS28CRP, DAS28-ESR and SDAI and CDAI scores asserting that US-CLARA was a valid and sensitive tool to determine disease activity status in RA. ${ }^{32}$

The $\mathrm{LoA}$ is $9.74 \pm 0.66$, and the grade is $\mathrm{A}$. This item has the highest agreement rate. Since there was no statistically significant difference between the two voting rounds, the item remained unchanged.

3. "In case of active disease, patients should have frequent follow-ups (every one-three months). The treatment should be re-adjusted if clinical improvement cannot be obtained in three months or the treatment goal cannot be reached within six months."

The term "with regard to composite indices" that was available in Turkish Compliance and Adaptation of EULAR 2013 recommendations for the management of RA was subtracted since it is presented in detail in explanations. ${ }^{11}$

The use of composite disease activity indices is strongly recommended by the EULAR. These composite measures include tender and swollen joint counts as well as acute phase reactants, patient's health assessment, and the ACR/EULAR remission criteria.

Our committee advised using disease activity measures including SDAI, CDAI, and DAS28.
SDAI and CDAI-based remission criteria have been reported to perform better than DAS28CRP-based remission criteria. ${ }^{30,33}$ In a study comparing SDAI and CDAI in RA patients, it was shown that CDAI performed as well as SDAI, and the CDAI was recommended due to its independence of acute phase reactants. ${ }^{34}$ In a novel study, it was observed that almost $15 \%$ of remitters defined by DAS28-CRP had at least three swollen joints and only 39\% of patients with DAS28-CRP $<1.9$ and 24\% with DAS28-ESR $<2.2$ met the Boolean remission definition indicating the limitation of DAS28 to describe remission adequately. ${ }^{31}$

On the other hand, according to the present health insurance system, payment conditions of bDMARDs are based on DAS28 scores. If a patient with RA has DAS28 score higher than 5.1 , despite use of three different csDMARDs for at least three months per each csDMARD, bDMARDs or tsDMARDs can be prescribed. For most bDMARDs and the tsDMARD, an improvement of at least 0.6 in DAS28 score by three months is required for bDMARDs to be continued for the following three months. Then, at the end of six months, if total improvement in the DAS28 score is at least 1.2 units, then treatment with bDMARDs can be continued for the following six months.

The LoA is $9.41 \pm 0.80$ and the grade is $\mathrm{A}$.

\section{4. "Methotrexate should constitute a part of the first treatment regimen."}

Although the expert panel was on agreement that MTX should be started as the first agent either as monotherapy or combined therapy, some discrepancies about the dose and route of administration arose. Some experts remarked beginning with $7.5 \mathrm{mg} /$ week dose and escalating the dose monthly up to $20-25 \mathrm{mg} /$ week while others prescribed $15 \mathrm{mg}$ /week as the initial dose. The majority of experts indicated that they did not exceed MTX doses of $25 \mathrm{mg} /$ week in their daily practice. It was indicated that if the response was not sufficient after the oral dose of $15-20 \mathrm{mg}$ /week, higher doses should be given subcutaneously. The expert panel also discussed when MTX should be administered subcutaneously. Some experts highlighted the results of studies where systemic exposure of subcutaneous (SC) MTX continued increasing particularly at doses $\geq 15 \mathrm{mg} /$ week 
compared to oral route that plateaus. ${ }^{35}$ Also, some experts stated that they occasionally began MTX subcutaneously without trying the oral route owing to superior bioavailability. They pointed out a study suggesting that initiation of MTX therapy subcutaneously at a dosage of $15 \mathrm{mg}$ /week for a sufficient period to perform dose escalation was superior to initiation of MTX therapy by the oral route. ${ }^{36}$ Our national healthcare insurance system permits SC use of MTX even as the initial therapy.

The definition of optimal MTX dose was defined in an expert opinion of a broad international panel of rheumatologists in the $3 \mathrm{E}$ initiative as starting at $10-15 \mathrm{mg} /$ week, with dose escalation of $5 \mathrm{mg}$ every two-four weeks up to $20-30 \mathrm{mg} /$ week, depending on clinical response and tolerability. Parenteral administration was recommended to be considered in case of inadequate clinical response or intolerance in this guideline. ${ }^{37}$

In a recent study to describe the optimal dose of MTX and evaluate adherence to it in daily clinical practice in the Étude et Suivi des Polyarthrites Indifférenciées Récentes (ESPOIR) early RA cohort, it was reported that optimal MTX dose was reached in only $26.4 \%$ of 288 RA patients. They noted that optimal MTX dose was more efficacious than non-optimal doses with regard to remission and function in early RA albeit no significant impact on radiographic progression over two years. ${ }^{38}$ In a recent review, it was alleged that there was no evidence that the benefit of biologic monotherapy was better than MTX in MTX-naive patients advocating the current practice of using MTX as the first-line agent in MTX-naive RA patients. ${ }^{39}$

The LoA is $9.67 \pm 0.68$ and the grade is A. Since there was no statistically significant difference between the two voting rounds, the item remained unchanged.

\section{5. "If MTX cannot be used because of contraindications or intolerance, LEF or SSZ should be started as a part of the first treatment regimen."}

Some experts of the committee indicated that they also used hydroxychloroquine at a dose of $5 \mathrm{mg} / \mathrm{kg} /$ day frequently in their routine practice. Although not as an initial therapeutic, they emphasized its role in mild patients and as a compound of combination therapies. Also, its beneficial effects in lipid and glucose metabolism were underlined. ${ }^{40}$ In several studies, the efficacy of LEF at a dose of $20 \mathrm{mg} /$ day was reported not to be significantly different from MTX and SSZ. ${ }^{4}$ In a recent meta-analysis, LEF was reported to display similar efficacy with MTX in terms of reduction in CRP levels, doctor's assessment of the disease activity, and amelioration of the quality of life whereas the percentage of patients attaining ACR20 response and reduction in swollen joint count was more favorable in MTX group. ${ }^{42}$ In another study to compare LEF with placebo and SSZ in active RA, LEF and SSZ were reported to provide similar overall efficacy although the decrease in the health assessment questionnaire of the LEF group was significantly greater than the SSZ group at four, 12, and 24 weeks, and there were significant differences between LEF and SSZ groups at four weeks in tender and swollen joint counts, patient's and physician's overall assessments, pain intensity, and CRP levels. ${ }^{43}$ In a recent meta-analysis evaluating the efficacy of LEF as the first-line DMARD, LEF was reported to be as efficacious as MTX. However, the reduction in the swollen joint count was more prominent in the MTX group. LEF was noted to cause greater increase in liver enzymes, but fewer gastrointestinal complaints than MTX. $^{42}$ Nonetheless, our health insurance system does not cover first-line use of LEF if intolerance or contraindication to MTX is lacking. Besides MTX, LEF is widely preferred as a comedication with bDMARDS to overcome immunogenicity in our expert panel.

The LoA is $9.41 \pm 0.75$ and the grade is A. Since there was no statistically significant difference between the two voting rounds, the item remained unchanged.

6. "In the periods of csDMARD initiation or change, glucocorticoids (GCs) should be considered for short-term use with different dose and administration routes; however, it should be tapered rapidly when the clinical condition permits."

The expert panel emphasized the significance of dose reduction of GCs as clinically feasible. The term "tapered rapidly when the clinical condition permits" was discussed. Majority of experts stated 
that GCs should be ceased approximately at the third month. One member asserted that GCs should preferably not be given for more than two months. Some members explained that they preferred GCs as bridge therapy and on disease flares. However, some experts $(n=11)$ told that discontinuation of the GCs was not possible in certain patients with high disease activity. They also noted maintaining doses of $2.5-5 \mathrm{mg} /$ day prednisolone considering its disease modifying effect. On the other hand, opponent experts claimed that using chronic low-dose (daily dose of $5 \mathrm{mg}$ or less prednisone per day) GCs should be regarded as a sign of incorrect treatment strategy. They alleged that the dependence on GCs may be a consequence of not escalating MTX dose rapidly, or retardation of the biologic therapy.

In a recent study on $\mathrm{RA}$ patients that have been receiving prednisolone $5 \mathrm{mg} /$ gün for $\geq 6$ months, high prevalence of adrenal insufficiency determined with inadequate response to the synthetic adrenocorticotropic hormone test was reported. ${ }^{44}$ In a population based cohort study, a dose-related association of GCs and increased cardiovascular as well as all-cause mortality was reported. The mortality risk was lower in patients that did not receive GCs or those with GC treatment duration of less than 10 years. ${ }^{45-47}$ According to German Rheumatoide Arthritis: Beobachtung der Biologika-Therapie (RABBIT) biologic registry analyzing the incidence of serious infections, the authors reported a significant association between the GC dose and the magnitude of the risk. ${ }^{48}$

Related to nightly activation of the inflammatory response, administration of exogenous GCs in midnight has evolved as "chronotherapy" ${ }^{49}$ In a double-blind randomized controlled trial (RCT), low-dose prednisone with modified release added to the ongoing DMARD treatment was shown to induce a significant effect on disease activity and health-related quality of life compared to placebo. ${ }^{50}$ In relation with chronotherapy, new formulations of GCs including modified or delayed-release prednisone are arising. Recently, studies with selective GC receptor agonists revealed favorable outcomes in a phase II clinical trial, and liposomal prednisolone is under evaluation in a phase III clinical trial. The GLORIA (Glucocorticoid Lowdose Outcome in RheumatoId Arthritis Study) trial assessing the safety and efficacy of low-dose
GC therapy (5 mg/day prednisone, two years) versus placebo is expected to procure novel insights. ${ }^{51-53}$

The LoA is $9.22 \pm 1.01$ and the grade is A. Since there was no statistically significant difference between the two voting rounds, the item remained unchanged.

\section{7. "If the treatment goal cannot be reached with the first treatment regimen, in the absence of poor prognostic factors, other csDMARDs should be initiated."}

As depicted by the EULAR, poor prognostic factors are moderate to high disease activity despite csDMARD therapy, high acute phase reactant levels, high swollen joint counts, rheumatoid factor (RF) and/or ACPA positivity (particularly at high titers), early erosions, failure of two or more csDMARDs, and combinations of these factors. ${ }^{6,54-56}$ Prognostic factors, still under investigation, may vary in clinical researches and include smoking, Doppler ultrasound activity, and bone edema in MRI. ${ }^{57-62}$

Results of the studies to compare the efficacy of csDMARD combinations and TNFi therapy are conflicting. In an open cohort study on veterans with RA, patients were reported to be significantly more persistent and adherent in TNFi+ MTX combination therapy than triple combination therapy with csDMARDs. However, the results of the study seem difficult to extrapolate to the usual RA population principally consisting of females as it is in the RACAT (Rheumatoid Arthritis: Comparison of Active Therapies in Patients with Active Disease Despite MTX Therapy) study indicating non-inferiority of triple combination therapy to etanercept+MTX in terms of DAS28, radiographic progression, pain, and healthrelated quality of life. ${ }^{63,64}$ In a recent double-blind non-inferiority trial based on the RACAT trial, RA patients responding suboptimally to MTX were randomized to take triple csDMARD or MTX+etanercept therapies latter of which was noted to be significantly less durable. Considering the substantial cost differences, similar clinical outcomes, and treatment durability, the authors concluded that csDMARD combinations may be preferred as the first choice over biologic agent combinations in case of inadequate response to MTX. ${ }^{65}$ 
In a recent review comparing MTX and MTXbased triple DMARD combinations with biologic DMARD/tofacitinib treatment approaches, $\mathrm{MTX}+\mathrm{SSZ}+\mathrm{HCQ}$ ("triple therapy") was found to be superior to oral MTX monotherapy and similar to MTX+biologic therapy for ACR50 response, both in MTX-naive and MTX-resistant patients. ${ }^{66}$ These data would substantiate use of combination therapy in patients without unfavorable prognostic factors. However, another systematic literature review propounds better efficacy of TNFi+MTX over triple therapy when administered as second-line treatment in case of inadequate response to MTX monotherapy, both on clinical and structural outcomes albeit no difference in functional improvement or adverse effects. ${ }^{67}$ Therefore, conflicting results of different studies denote individualized treatment decisions.

The LoA is $9.33 \pm 0.88$ and the grade is A. Since there was no statistically significant difference between the two voting rounds, the item remained unchanged.

\section{8. "If the treatment goal cannot be reached with the first treatment regimen, in the presence of poor prognostic factors, a bDMARD or tsDMARD addition should be considered."}

The LoA of this item in the first TLAR voting was lower than EULAR's despite being considered nonsignificant (Figure 2). The phrase "current practice would be to start with a bDMARD" was suggested to be omitted to emphasize that non-TNF biologics and tsDMARDs may also be preferred after csDMARD failure in a case with poor prognostic factors. This alteration was approved due to gathering a $>70 \%$ participation and significantly increased LoA after the revision.

The experts noted that generally a bDMARD is the first treatment choice after failure with conventional drugs in Turkey. Infliximab 3-5 mg/kg/6-8 week intravenous (IV), etanercept $50 \mathrm{mg} /$ week SC, adalimumab $40 \mathrm{mg} / 2$ week SC, golimumab $50 \mathrm{mg} / \mathrm{month} \mathrm{SC}$, abatacept $125 \mathrm{mg} /$ week SC or $10 \mathrm{mg} / \mathrm{kg} / \mathrm{month} \mathrm{IV}$, certolizumab $200 \mathrm{mg} / 2$ week SC, rituximab $1000 \mathrm{mg} / 2$ week every six months IV, tocilizumab $8 \mathrm{mg} / \mathrm{kg} / \mathrm{month} \mathrm{IV}$, and bs-infliximab, CT-P13 3-5 mg/kg/6-8 week IV, have been approved in our country and have been administered safely for a long while. The long term extension studies of these agents substantiate their use in clinical practice. ${ }^{68,69} \mathrm{By}$ the expert committee, particularly for patients with chronic diseases impeding csDMARD therapy including renal and hepatic failure, bDMARDs were enounced as candidates for the first-line treatment. However, some members of the committee referred to favorable effects of tsDMARDs. In the former TLAR RA treatment recommendations in 2013, no proposal for tofacitinib was held out due to scarcity of clinical experience. In the meantime, depending on the three-year real life experience of efficacy and safety of the tsDMARD, our expert committee stated that tofacitinib might also be preferred after failure of csDMARDs. Furthermore, tofacitinib is permitted in high disease activity (DAS28 $>5.1$ ) by our national health insurance system after three csDMARD failures without necessity of a bDMARD failure. In a recent meta-analysis comparing the efficacy and tolerability of tofacitinib versus bDMARDs for the treatment of non-bDMARD resistant, moderate to severe RA patients, tofacitinib had similar efficacy and discontinuation rates compared to bDMARDs in most cases. ${ }^{70}$ In another study, tofacitinib was found to be efficacious in both bDMARD-naive and bDMARD-resistant patients. They reported that the response rate was even better in bDMARD-naive patients with a similar safety profile. ${ }^{71}$

Besides, the use of csDMARD combination or a TNFi or a non-TNF bDMARD or tsDMARD was recommended after csDMARD monotherapy failure and high disease activity in ACR 2015 Guideline for the Treatment of RA. ${ }^{9}$ Also, the National Institute For Health and Care Excellence (NICE) guideline recommends using tofacitinib with MTX as an option for treating active RA in adults responding inadequately to combination of csDMARDs. The guideline also states that tofacitinib can be used as monotherapy in patients who cannot use MTX as a comedication due to contraindication or intolerance. ${ }^{72}$

In a recent $\mathrm{RCT}$ comparing oral baricitinib with placebo and adalimumab (ADA) in patients with inadequate response to MTX, baricitinib was reported to lead to significant clinical response determined with percentage of patients attaining ACR20 response compared with placebo 
and ADA. Decrease in neutrophil counts and increase in creatinine and low-density lipoprotein cholesterol levels were noted for baricitinib. ${ }^{73}$ Nevertheless, baricitinib is not available in our country yet.

Some members of the expert panel emphasized the favorable effects of rituximab (RTX) as the initial biologic therapy particularly in seropositive biologic-naive patients. Furthermore, an openlabel, randomized controlled, non-inferiority trial, tumour necrosis factor inhibition versus rituximab for patients with rheumatoid arthritis who require biological treatment (ORBIT), revealed that RTX was not inferior to initial TNFi therapy in seropositive biologic-naive RA patients. Although the reduction in DAS28 scores was not found to be statistically significant across the groups of RTX and ADA/etanercept, the authors depicted that RTX was more cost-saving than TNFi strategies. ${ }^{74} \mathrm{~A}$ randomized controlled trial to compare MTX+LEF and MTX+low-dose RTX therapies on $40 \mathrm{RA}$ patients remarked that LEF and low-dose RTX added to MTX showed similar efficacy in achieving ACR20, ACR50 and ACR70 response with similar adverse events ensuring a favorable cost profile for patients in developing countries. ${ }^{75}$

Moreover, some members emphasized that induction therapy with biologics was promising. The literature indicates that an early intensive approach to patients with early-onset RA would have the potential to reduce adverse effects of drugs and long-term health costs. ${ }^{76,77}$ The post hoc analysis of the Behandel Strategieen (BeSt) study on DMARD-naive patients showed that bDMARD discontinuation was possible particularly in patients receiving infliximab (IFX)+MTX as induction therapy compared to patients administered late IFX+MTX combination therapy indicating the role of bDMARDs in recent onset disease. ${ }^{78}$ On the other hand, as revealed in the the High Induction Therapy with Anti-Rheumatic Drugs (HIT HARD) study, clinical outcomes (DAS28 reduction) at $48^{\text {th }}$ week were similar between patients discontinuing ADA after ADA+MTX induction therapy of six months and patients using MTX+placebo. However, reduction in radiographic progression at $48^{\text {th }}$ week was reported to be higher in patients having induction therapy with ADA+MTX when compared to MTX monotherapy. ${ }^{79}$ In the Early rheumatoid arthritis treated with tocilizumab, methotrexate, or their combination (U-ACT Early) trial; a two-year, multicenter, randomized study to evaluate the efficacy and safety of tocilizumab with or without MTX, and MTX monotherapy on DMARD-naive RA patients, $86 \%$ of patients receiving tocilizumab+MTX versus $88 \%$ of patients in tocilizumab arm, and $77 \%$ of the MTX arm achieved sustained remission. The authors concluded that immediate initiation of tocilizumab with or without MTX was effective to establish sustained remission in early RA patients, also indicating tocilizumab's role as monotherapy. ${ }^{80}$ In the Certolizumab-Optimal Prevention of joint damage for Early RA (C-OPERA) trial comparing combination therapy of certolizumab pegol+MTX and MTX+placebo as first-line treatment for MTX-naive, early RA patients with poor prognostic factors, certolizumab and MTX combination was shown to be superior in inhibition of structural damage determined by modified Total Sharp Score in $24^{\text {th }}$ and $52^{\text {th }}$ weeks, and reduction of signs and symptoms. ${ }^{81}$ The post hoc analysis of the Optimal Protocol for Methotrexate and Adalimumab Combination Therapy in Early Rheumatoid Arthritis (OPTIMA) study, which aimed to compare MTX monotherapy and MTX+ADA in early RA patients, revealed that a significantly greater rate of patients receiving combination of ADA+MTX compared to MTX monotherapy achieved low disease activity determined with DAS28-CRP $<3.2$, superior radiographic outcomes, and better function at the $26^{\text {th }}$ week. ${ }^{82}$

In an analysis to evaluate the cost-effectiveness of the treatment strategies in the Treatment of Early Aggressive Rheumatoid Arthritis (TEAR) trial, the immediate triple DMARD combination and etanercept strategies were more efficacious than step-up strategies. Depending on the higher price of etanercept, step-up etanercept and initial etanercept strategies had higher costs compared to step-up triple combination and initial triple combination. Additionally, initial triple combination was the least costly and most efficacious treatment strategy within the first two years. However, when results of the fifth year are considered, initial etanercept therapy was more effective than initial triple combination despite higher treatment costs displaying an incremental cost-effectiveness ratio of $\$ 12.5$ million per Quality Adjusted Life Years. ${ }^{83}$ 
The LoA increased from $8.0 \pm 2.39$ to $9.44 \pm 0.93$ after the revision. The second version was accepted due to the statistically significant difference between two forms $(p=0.002)$. The grade of the item is $\mathrm{A}$.

9. "Biologic DMARDs and tsDMARDs should be used together with a csDMARD. For patients who cannot use csDMARDs along with these medications, IL-6 inhibitors or tsDMARDs may have beneficial effects over other bDMARDs."

There was a consensus on combined use of all bDMARDs and tsDMARD with csDMARDs within the expert panel. However, they stated that they occasionally had to use biologics as monotherapy for several reasons. This may have caused lower LoA of the ninth item in the first TLAR voting compared to EULAR's original voting. The experts put forward that tocilizumab and tofacitinib with proven monotherapy efficacy may be preferred for patients to whom csDMARDs cannot be given.

In the Actemra versus Methotrexate doubleBlind Investigative Trial In mONotherapy (AMBITION) study, tocilizumab monotherapy was found to be more efficient than MTX monotherapy, with a favorable benefit-risk ratio in biologic and MTX-naive patients. In the long-term extension studies, tocilizumab monotherapy was reported to exhibit durable efficacy over time without any association between serious adverse events and duration of tocilizumab exposure. ${ }^{84}$

According to a multicenter, double-blind, double-dummy, randomized phase III trial investigating the efficacy and safety of tocilizumab in early RA patients, proportions of patients achieving ACR20, ACR50 and ACR70 responses were similar at weeks 52 and 104 in the $8 \mathrm{mg} / \mathrm{kg}$ tocilizumab monotherapy and $8 \mathrm{mg} / \mathrm{kg}$ tocilizumab+MTX groups being maintained through 104 weeks. ${ }^{85}$ The ACTemra (tocilizumab) RAdiographic studY (ACT-RAY) trial assessed the efficacy and safety of adding tocilizumab to ongoing MTX treatment versus switching to tocilizumab monotherapy in active RA patients with inadequate response to MTX. Adding tocilizumab to MTX and switching to tocilizumab resulted in good clinical outcomes despite higher rate of add-on patients displaying no radiographic progression than switch patients. Although no major overall difference was reported between these two treatment strategies, authors concluded that addition of MTX may be considered if tolerated. ${ }^{86}$

In a randomized, double-blind, placebocontrolled trial, tofacitinib monotherapy at doses of $5 \mathrm{mg}, 15 \mathrm{mg}$, and $30 \mathrm{mg}$ twice daily was compared with placebo. This study indicated that tofacitinib monotherapy at a dose of $5 \mathrm{mg}$ or $10 \mathrm{mg}$ twice daily reduced signs and symptoms of RA and improved physical function. ${ }^{87}$ In a post hoc analysis to compare the efficacy of tofacitinib monotherapy (5 or $10 \mathrm{mg}$ two times a day) and MTX monotherapy in 956 MTX-naive adult RA patients, clinical and functional outcomes were found to be similar in early and established RA with either MTX or tofacitinib; however, significantly greater improvements were detected with tofacitinib $5 \mathrm{mg}$ two times a day in early versus established $\mathrm{RA}$ at the $24^{\text {th }}$ month. ${ }^{88}$ However, in the ORAL STRATEGY study, a double-blind, randomized controlled non-inferiority trial comparing oral tofacitinib monotherapy, oral tofacitinib+MTX, and SC ADA (40 mg every other week)+MTX, non-inferiority was noted for tofacitinib+MTX versus ADA and MTX but not for tofacitinib monotherapy versus either ADA+MTX or tofacitinib+MTX. ${ }^{89}$ In another study evaluating the treatment costs of treatment strategies including tofacitinib, adalimumab, etanercept, certolizumab and tocilizumab, it was alleged that tofacitinib $5 \mathrm{mg}$ two times a day is a lower-cost per patient treatment agent either in monotherapy or combination therapy after MTX failure compared to TNFi with or without MTX. Additionally, tofacitinib+MTX was considered to be a lower-cost treatment option than ADA+MTX in patients with inadequate response to $\mathrm{TNFi} .{ }^{90}$

Some experts of the panel put forward the studies supporting the use of etanercept as monotherapy. In the Add Enbrel or Replace Methotrexate (ADORE) study on patients with inadequate response to MTX, rates of patients attaining $>1.2$ units of DAS28 response were similar across MTX+etanercept and etanercept monotherapy groups. ${ }^{91}$ In a recent meta-analysis, etanercept or tocilizumab were asserted to be the optimal therapeutic choices for some patients 
requiring treatment with biological monotherapy. ${ }^{92}$ On the other hand, in an observational study comparing etanercept monotherapy and MTX+etanercept, combination therapy was found to be superior in achieving DAS28 remission and functional remission defined with the Funktionsfragebogen Hannover Functional Ability Questionnaire. As for the reduction in swollen and tender joint counts, the protocols were reported to be similar. ${ }^{93}$

The NICE guideline permits agents including adalimumab, etanercept, certolizumab pegol and tocilizumab for monotherapy in patients with contraindication or intolerance to MTX. ${ }^{94}$

The LoA is $8.74 \pm 1.40$ and the grade is A. Since there was no statistically significant difference between the two voting rounds, the item remained unchanged.

\section{0. "In case of bDMARD or tsDMARD failure, treatment with another bDMARD or tsDMARD should be given. In case of one TNFi failure, another TNFi or medication with a different mechanism may be considered."}

After failure with a TNFi therapy, some members of the panel recommended using agents with different mechanism such as non-TNF bDMARDs or tsDMARDs. Likewise, ACR 2015 guideline for the treatment of RA recommends using a non-TNF biologic over another TNFi in case of moderate or high disease activity despite using a single TNFi. Furthermore, they suggest adding one or two csDMARDs in patients with moderate to high disease activity despite TNFi monotherapy. ${ }^{9}$ Our experts also suggested checking if the patient has csDMARD comedication along with the bDMARD before deciding on a failure of bDMARD.

In a recent open label $\mathrm{RCT}$ among patients previously treated with TNFi drugs and inadequate primary response, a non-TNF biologic agent was found to be more effective in attaining good or moderate disease activity response at 24 weeks than a second TNFi. Furthermore, higher proportion of patients in the non-TNF group displayed low disease activity than those in TNFi group at the $52^{\text {nd }}$ week..$^{95}$ In a single-arm study to evaluate the efficacy of etanercept after primary or secondary failure with ADA, switching to etanercept was offered as a therapeutic option. It was concluded that in case of anti-ADA antibodies and secondary failure, switching to etanercept may provide further contribution. ${ }^{96}$ Also, the NICE guideline recommends RTX+MTX for the treatment of severely active RA after the failure of the first TNFi. For patients to whom RTX cannot be given due to adverse effects or contraindication, ADA, etanercept, IFX, certolizumab, or abatacept may be given in combination with MTX. ${ }^{97}$

In a retrospective longitudinal study, switching to a new mechanism of action-DMARD was found to result in better treatment persistence and greater reduction in CDAI scores despite being insignificant after adjustment according to baseline disease activity. ${ }^{98}$ Consequently, overall findings indicate that either TNF inhibition or suppression with other mechanisms may be preferred after single TNFi failure. However, despite substantiation of usage of an agent with different mechanism by some members of the expert panel, the item remained unchanged.

The experts also pointed out that biosimilars exhibited similar efficacy to bio-original molecules in numerous studies. In the Programme evaLuating the Autoimmune disease iNvEstigational drug cT-p13 in RA patients (PLANETRA) study, it was shown that biosimilar IFX and bio-original IFX lead to similar outcome in terms of efficacy (including radiographic progression), immunogenicity, and safety profile.99 In a randomized, doubleblind trial to demonstrate bioequivalence of GP2013 (biosimilar RTX) and the reference RTX molecule; efficacy, safety and immunogenicity profiles of GP2013 and RTX were noted to be comperable. ${ }^{100}$ In another study comparing efficacy and safety of biosimilar ADA to the innovator ADA, biosimilar ADA was shown to be non-inferior to bio-original ADA with a similar efficacy and safety profile. ${ }^{101}$ Biologic therapies, despite contributing significantly to the treatment of RA, are expensive and many patients cannot reach this therapy. Biosimilar versions of these biologics may enhance the accessibility of these drugs with a highly similar quality and efficacy profile at an acceptably lower cost. ${ }^{102}$ However, some members of our expert panel alleged that the biosimilar molecule available in our country currently was not adequately cost-saving. Besides, it was emphasized that if loss of effect occurs 
with one boDMARD, the bsDMARD of the same molecule should not be used. Also, the same rule of not initiating the boDMARD is valid if effect loss occurs to its bsDMARD. ${ }^{6,103}$

The LoA is $9.0 \pm 1.47$ and the grade is A. Since there was no statistically significant difference between the two voting rounds, the item remained unchanged.

\section{1. "In case of persistent remission after tapering GCs in a patient using csDMARDs as comedication, dose reduction of bDMARDs may be considered."}

The expert panel discussed the description of "persistent remission." Complying with EULAR's opinion, the general view unified on a duration of six months. The SLR revealed that several clinical factors including increased disease duration, higher baseline DAS, increased baseline tender joint count, female sex, increased age, and higher baseline functional impairment scores were associated with lower likelihood to reach sustained remission while using MTX as comedication was associated with increased likelihood. ${ }^{104}$

The expert panel also discussed the regimens to follow after achievement of sustained remission. Members noted that the first drug to taper was bDMARDs after having tapered GCs. They stated preferring dose reduction or spacing intervals instead of quitting anti-TNF therapy abruptly. Accordingly, the $14^{\text {th }}$ recommendation of ACR 2015 RA recommendations deals with this issue and strongly recommends continuing the TNFi, non-TNF biologic and tsDMARD instead of discontinuing. ${ }^{9}$ The literature presents substantiating data showing that successful biological drug cessation is possible but dose reduction is more consistently successful. The majority of patients who are reinitiated the biologics after a flare have been reported to recover and maintain their previous response to therapy. ${ }^{76}$ In "Sustained remission with etanercept tapering in early rheumatoid arthritis" study on MTX-naive early RA patients, sustained remission was achieved by a significantly higher proportion of patients in etanercept $25 \mathrm{mg} /$ week+MTX group than MTX only patients. ${ }^{105}$ The results were corroborative also in the maintenance, reduction, or withdrawal of etanercept after treatment with etanercept and methotrexate in patients with moderate rheumatoid arthritis (PRESERVE) trial. In the trial comparing the effects of down-titration and withdrawal of etanercept, the proportion of patients sustaining low disease activity was significantly higher in patients with reduced etanercept dose than patients whose etanercept therapy was withdrawn using MTX only. ${ }^{106}$ The maintenance treatment using abatacept with dose reduction after achievement of low disease activity in patients with rheumatoid arthritis (MATADOR) study revealed that decreased dose of IV abatacept (250 mg/month) would be a conceivable maintenance therapy following the achievement of remission or low disease activity. ${ }^{107}$

A recent meta-analysis revealed that discontinuation of bDMARDs was associated with an increased risk of radiographic progression compared with bDMARD continuation. It was also stated that down-titration of bDMARDs increased risk for losing remission but did not increase the risk for losing low disease activity state or radiographic progression. Moreover, the risk of losing low disease activity after bDMARD discontinuation was reported to be lower among patients with recent RA (37.2\%) than those with established RA (52.6\%). ${ }^{108}$ On which patients down-titration of the biologic therapy should be considered or delayed. ${ }^{109}$

Beyond merely clinical remission determined with tender and swollen joint counts, imaging or serologic remission may also be taken into account. ${ }^{110}$ In a study on guidance of ultrasound for de-escalation of biologics, the presence of power Doppler positive synovitis in any joint at baseline was found to be predictive of flares. ${ }^{111}$

The LoA is $9.3 \pm 1.14$ and the grade is A. Since there was no statistically significant difference between the two voting rounds, the item remained unchanged.

\section{2. "In case of persistent remission after tapering bDMARDs, dose reduction of the csDMARD may be considered."}

This item has gained higher LoA in TLAR voting compared to EULAR's original voting (Figure 2). Our expert panel stated that in case of sustained remission, they usually tapered the dose of csDMARDs, rather than stopping csDMARD therapy in their daily practice. 


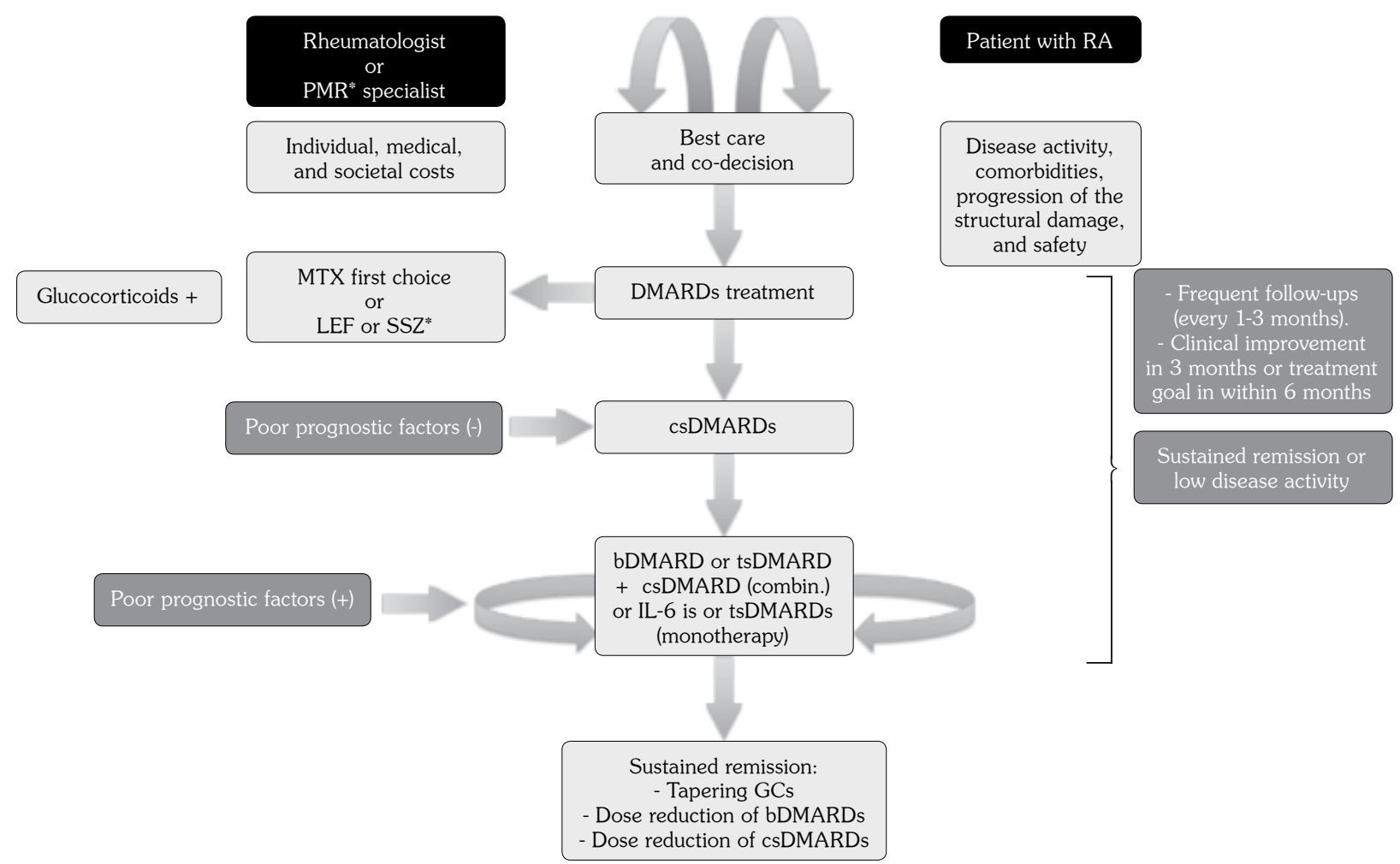

Figure 3. Turkish League Against Rheumatism 2018 recommendations for the management of rheumatoid arthritis. PMR: Physical Medicine and Rehabilitation; RA: Rheumatoid arthritis; DMARD: Disease modifying anti-rheumatic drug; MTX: Methotrexate; LEF: Leflunomide; SSZ: Sulphasalazine; csDMARD: Conventional synthetic disease modifying anti-rheumatic drug; combin: Combination; monot: Monotherapy; GC: Glucocorticoid; bDMARD: Biologic disease modifying anti-rheumatic drug; tsDMARD: Targeted synthetic disease modifying antirheumatic drug; IL: Interleukin; IL-6is: IL-6 inhibitors; " In intolerance to MTX or when it cannot be used.

In a study evaluating RCTs and observational studies, authors pointed out that the step-down DMARD combinations were effective, and, in early RA, attained persistent clinical responses. Besides, they noted that drug-free remission was accessible in a minority of cases. Some patients who achieve long-standing remission with DMARDs may flare; however, reinitialization of the DMARDs usually ameliorates these flares. Currently, immunoglobulin M (IgM)-RF and ACPApositivity were found to be the best predictors of flares on discontinuing DMARDs. Further research should be performed to determine the patients at risk of experiencing disease flares. ${ }^{112}$

In another study, authors reported that 9-15\% of RA patients who received conventional therapy achieved sustained DMARD-free remission. Six factors, including acute onset, short symptom duration before inclusion, absence of IgM-RF, absence of human leukocyte antigen shared epitope alleles, little radiographic damage at baseline and not smoking, were found to be associated with sustained DMARD-free remission. ${ }^{113}$

In a meta-analysis, it was shown that withdrawal of DMARD treatment in established RA increased the risk of flares, independent of the DMARD used. Disease activity should be monitored strictly in these patients to restart their previous DMARD therapy as soon as possible in case of a flare. ${ }^{114}$ Data indicating that patients may still have ongoing erosive process should be borne in mind when DMARDs are being withdrawn. ${ }^{115,116}$

The LoA is $9.44 \pm 0.75$ and the grade is A. Since there was no statistically significant difference between the two voting rounds, the item remained unchanged. The items of TLAR 2018 recommendations for the management of RA were summarized in Figure 3.

In conclusion, this is the third study of the TLAR to compose the treatment recommendations for RA principally based on EULAR recommendations 
and the recent literature. National health insurance systems designate their regulations considering the recent literature. Therefore, we have performed this study to provide an acceptable, evidence-based and sustainable treatment algorithm for the use of Turkish rheumatologists and physical medicine and rehabilitation specialists and to constitute a reference for our national health insurance system. Our results revealed that the attitude in RA management among Turkish experts bears high resemblance to the European approach. The nuances in specialties of physicians dating back to the constitutional regulations have led to some alterations in overarching principles.

Turkish League Against Rheumatism pursues its activities to generate new management recommendations for rheumatic diseases periodically to illuminate the future and expand the awareness in the field of rheumatology in Turkey.

\section{Declaration of conflicting interests}

The authors declared no conflicts of interest with respect to the authorship and/or publication of this article.

\section{Funding}

The authors received no financial support for the research and/or authorship of this article.

\section{REFERENCES}

1. Arora S, Rafiq A, Jolly M. Management of rheumatoid arthritis: Review of current guidelines. Journal of Arthroscopy and Joint Surgery 2016;3:45-50.

2. Smolen JS, Aletaha D, Koeller M, Weisman MH, Emery P. New therapies for treatment of rheumatoid arthritis. Lancet 2007;370:1861-74.

3. Smolen JS, van der Heijde D, Machold KP, Aletaha $\mathrm{D}$, Landewé R. Proposal for a new nomenclature of disease-modifying antirheumatic drugs. Ann Rheum Dis 2014;73:3-5.

4. Smolen JS, Landewé R, Breedveld FC, Dougados M, Emery P, Gaujoux-Viala C, et al. EULAR recommendations for the management of rheumatoid arthritis with synthetic and biological diseasemodifying antirheumatic drugs. Ann Rheum Dis 2010;69:964-75.

5. Smolen JS, Landewé R, Breedveld FC, Buch $\mathrm{M}$, Burmester G, Dougados $\mathrm{M}$, et al. EULAR recommendations for the management of rheumatoid arthritis with synthetic and biological diseasemodifying antirheumatic drugs: 2013 update. Ann Rheum Dis 2014;73:492-509.
6. Smolen JS, Landewé R, Bijlsma J, Burmester G, Chatzidionysiou K, Dougados $\mathrm{M}$, et al. EULAR recommendations for the management of rheumatoid arthritis with synthetic and biological diseasemodifying antirheumatic drugs: 2016 update. Ann Rheum Dis 2017;76:960-77.

7. Saag KG, Teng GG, Patkar NM, Anuntiyo J, Finney C, Curtis JR, et al. American College of Rheumatology 2008 recommendations for the use of nonbiologic and biologic disease-modifying antirheumatic drugs in rheumatoid arthritis. Arthritis Rheum 2008;59:762-84.

8. Singh JA, Furst DE, Bharat A, Curtis JR, Kavanaugh AF, Kremer JM, et al. 2012 update of the 2008 American College of Rheumatology recommendations for the use of disease-modifying antirheumatic drugs and biologic agents in the treatment of rheumatoid arthritis. Arthritis Care Res (Hoboken) 2012;64:625-39.

9. Singh JA, Saag KG, Bridges SL Jr, Akl EA, Bannuru RR, Sullivan MC, et al. 2015 American College of Rheumatology Guideline for the Treatment of Rheumatoid Arthritis. Arthritis Rheumatol 2016;68:1-26.

10. Ataman Ş, Borman P, Evcik D, Aydoğ E, Ayhan F, Ylldizlar D, et al. Management of rheumatoid arthritis: Consensus Recommendations from the Turkish League Against Rheumatism. Turk J Rheumatol 2011;26:273-94.

11. Ataman Ş, Sarı Zühre S, İsmihan S, Özdemirel $\mathrm{E}$, Akıncı $\mathrm{T}$, Bodur $\mathrm{H}$, et al. Turkish Compliance and Adaptation of EULAR 2013 Recommendations for the Management of Rheumatoid Arthritis with Synthetic and Biological Disease-modifying Antirheumatic Drugs: Expert opinion of TLAR. Arch Rheumatol 2015;30:271-84.

12. Brozek JL, Akl EA, Alonso-Coello P, Lang D, Jaeschke R, Williams JW, et al. Grading quality of evidence and strength of recommendations in clinical practice guidelines. Part 1 of 3 . An overview of the GRADE approach and grading quality of evidence about interventions. Allergy 2009;64:669-77.

13. Riemsma RP, Kirwan JR, Taal E, Rasker JJ. Patient education for adults with rheumatoid arthritis. Cochrane Database Syst Rev 2003;2:CD003688.

14. Hammond A, Freeman K. One-year outcomes of a randomized controlled trial of an educationalbehavioural joint protection programme for people with rheumatoid arthritis. Rheumatology (Oxford) 2001;40:1044-51.

15. Masiero S, Boniolo A, Wassermann L, Machiedo $\mathrm{H}$, Volante D, Punzi L. Effects of an educationalbehavioral joint protection program on people with moderate to severe rheumatoid arthritis: a randomized controlled trial. Clin Rheumatol 2007;26:2043-50.

16. Hifinger M, Hiligsmann M, Ramiro S, Watson V, Severens JL, Fautrel B, et al. Economic considerations and patients' preferences affect treatment selection 
for patients with rheumatoid arthritis: a discrete choice experiment among European rheumatologists. Ann Rheum Dis 2017;76:126-32.

17. Allaire $\mathrm{SH}$, Prashker MJ, Meenan RF. The costs of rheumatoid arthritis. Pharmacoeconomics 1994;6:513-22.

18. Gabriel SE, Coyle D, Moreland LW. A clinical and economic review of disease-modifying antirheumatic drugs. Pharmacoeconomics 2001;19:715-28.

19. Ikeda K, Iwamoto T, Nakajima H. Perspective of ultrasound-guided strategy to reduce/discontinue biologics. Nihon Rinsho 2016;74:919-23. [Abstract]

20. Athanasakis K, Tarantilis F, Tsalapati K, Konstantopoulou T, Vritzali E, Kyriopoulos J. Costutility analysis of tocilizumab monotherapy in first line versus standard of care for the treatment of rheumatoid arthritis in Greece. Rheumatol Int 2015;35:1489-95.

21. Rat AC, Boissier MC. Rheumatoid arthritis: direct and indirect costs. Joint Bone Spine 2004;71:51824.

22. El Miedany Y, Youssef S, Mehanna AN, El Gaafary M. Development of a scoring system for assessment of outcome of early undifferentiated inflammatory synovitis. Joint Bone Spine 2008;75:155-62.

23. Combe B. Progression in early rheumatoid arthritis. Best Pract Res Clin Rheumatol 2009;23:59-69.

24. Aletaha D, Neogi T, Silman AJ, Funovits J, Felson DT, Bingham CO, et al. 2010 rheumatoid arthritis classification criteria: an American College of Rheumatology/European League Against Rheumatism collaborative initiative. Ann Rheum Dis 2010;69:1580-8.

25. Smolen JS, Aletaha D, McInnes IB. Rheumatoid arthritis. Lancet 2016;388:2023-38.

26. Mathew AJ, Danda D, Conaghan PG. MRI and ultrasound in rheumatoid arthritis. Curr Opin Rheumatol 2016;28:323-9.

27. Smolen JS, Breedveld FC, Burmester GR, Bykerk V, Dougados M, Emery P, et al. Treating rheumatoid arthritis to target: 2014 update of the recommendations of an international task force. Ann Rheum Dis 2016;75:3-15.

28. de Punder YM, Hendrikx J, den Broeder AA, Valls Pascual E, van Riel PL, Fransen J. Should we redefine treatment targets in rheumatoid arthritis? Low disease activity is sufficiently strict for patients who are anticitrullinated protein antibody-negative. J Rheumatol 2013;40:1268-74.

29. Kawashiri SY, Kawakami A, Iwamoto N, Fujikawa $\mathrm{K}$, Aramaki T, Tamai M, et al. Disease activity score 28 may overestimate the remission induction of rheumatoid arthritis patients treated with tocilizumab: comparison with the remission by the clinical disease activity index. Mod Rheumatol 2011;21:365-9.

30. Fleischmann R, van der Heijde D, Koenig AS, Pedersen R, Szumski A, Marshall L, et al. How much does Disease Activity Score in 28 joints ESR and CRP calculations underestimate disease activity compared with the Simplified Disease Activity Index? Ann Rheum Dis 2015;74:1132-7.

31. Schoels M, Alasti F, Smolen JS, Aletaha D. Evaluation of newly proposed remission cut-points for disease activity score in 28 joints (DAS28) in rheumatoid arthritis patients upon IL-6 pathway inhibition. Arthritis Res Ther 2017;19:155.

32. Salaffi F, Di Carlo M, Iannone F, Fedele AL, Epis $\mathrm{OM}$, Pellerito $\mathrm{R}$, et al. The UltraSound-CLinical ARthritis Activity (US-CLARA) index: Properties of a new composite disease activity index for rheumatoid arthritis. Semin Arthritis Rheum 2018;47:619-29.

33. Dhaon P, Das SK, Srivastava R, Dhakad U. Performances of Clinical Disease Activity Index (CDAI) and Simplified Disease Activity Index (SDAI) appear to be better than the gold standard Disease Assessment Score (DAS-28-CRP) to assess rheumatoid arthritis patients. Int J Rheum Dis 2017.

34. Aletaha D, Smolen J. The Simplified Disease Activity Index (SDAI) and the Clinical Disease Activity Index (CDAI): a review of their usefulness and validity in rheumatoid arthritis. Clin Exp Rheumatol 2005;23:100-8.

35. Schiff MH, Jaffe JS, Freundlich B.Head-tohead, randomised, crossover study of oral versus subcutaneous methotrexate in patients with rheumatoid arthritis: drug-exposure limitations of oral methotrexate at doses $\geq 15 \mathrm{mg}$ may be overcome with subcutaneous administration. Ann Rheum Dis 2014;73:1549-51.

36. Braun J, Kästner $P$, Flaxenberg $P$, Währisch J, Hanke P, Demary W, et al. Comparison of the clinical efficacy and safety of subcutaneous versus oral administration of methotrexate in patients with active rheumatoid arthritis: results of a six-month, multicenter, randomized, double-blind, controlled, phase IV trial. Arthritis Rheum 2008;58:73-81.

37. Visser K, Katchamart W, Loza E, Martinez-Lopez JA, Salliot C, Trudeau J, et al. Multinational evidencebased recommendations for the use of methotrexate in rheumatic disorders with a focus on rheumatoid arthritis: integrating systematic literature research and expert opinion of a broad international panel of rheumatologists in the $3 \mathrm{E}$ Initiative. Ann Rheum Dis 2009;68:1086-93.

38. Gaujoux-Viala C, Rincheval N, Dougados M, Combe B, Fautrel B. Optimal methotrexate dose is associated with better clinical outcomes than non-optimal dose in daily practice: Results from the espoir early arthritis cohort. Ann Rheum Dis 2017;76:2054-60.

39. Singh JA, Hossain A, Mudano AS, Tanjong Ghogomu E, Suarez-Almazor ME, Buchbinder R, et al. Biologics or tofacitinib for people with rheumatoid arthritis naive to methotrexate: a systematic review and network meta-analysis. Cochrane Database Syst Rev 2017 8;5:CD012657. 
40. Hage MP, Al-Badri MR, Azar ST. A favorable effect of hydroxychloroquine on glucose and lipid metabolism beyond its anti-inflammatory role. Ther Adv Endocrinol Metab 2014;5:77-85.

41. Golicki D, Newada M, Lis J, Pol K, Hermanowski $\mathrm{T}$, Tlustochowicz M. Leflunomide in monotherapy of rheumatoid arthritis: meta-analysis of randomized trials. Pol Arch Med Wewn 2012;122:22-32.

42. Alfaro-Lara R, Espinosa-Ortega HF, Arce-Salinas CA. Systematic review and meta-analysis of the efficacy and safety of leflunomide and methotrexate in the treatment of rheumatoid arthritis. Reumatol Clin 2017. pii: S1699-258X(17)30196-1.

43. Smolen JS, Kalden JR, Scott DL, Rozman B, Kvien TK, Larsen A, et al. Efficacy and safety of leflunomide compared with placebo and sulphasalazine in active rheumatoid arthritis: a double-blind, randomised, multicentre trial. European Leflunomide Study Group. Lancet 1999;353:259-66.

44. Borresen SW, Klose M, Baslund B, Rasmussen ÅK, Hilsted L, Friis-Hansen L, et al. Adrenal insufficiency is seen in more than one-third of patients during ongoing low-dose prednisolone treatment for rheumatoid arthritis. Eur J Endocrinol 2017;177:287-295.

45. Davis JM, Maradit Kremers H, Crowson CS, Nicola PJ, Ballman KV, Therneau TM, et al. Glucocorticoids and cardiovascular events in rheumatoid arthritis: a population-based cohort study. Arthritis Rheum 2007;56:820-30.

46. Wei L, MacDonald TM, Walker BR. Taking glucocorticoids by prescription is associated with subsequent cardiovascular disease. Ann Intern Med 2004;141:764-70.

47. Sihvonen S, Korpela M, Mustonen J, Huhtala H, Karstila K, Pasternack A. Mortality in patients with rheumatoid arthritis treated with low-dose oral glucocorticoids. A population-based cohort study. J Rheumatol 2006;33:1740-6.

48. Strangfeld A, Eveslage M, Schneider M, Bergerhausen HJ, Klopsch T, Zink A, et al. Treatment benefit or survival of the fittest: what drives the timedependent decrease in serious infection rates under TNF inhibition and what does this imply for the individual patient? Ann Rheum Dis 2011;70:1914-20.

49. Paolino S, Cutolo M, Pizzorni C. Glucocorticoid management in rheumatoid arthritis: morning or night low dose? Reumatologia 2017;55:189-97.

50. Buttgereit F, Mehta D, Kirwan J, Szechinski J, Boers M, Alten RE, et al. Low-dose prednisone chronotherapy for rheumatoid arthritis: a randomised clinical trial (CAPRA-2). Ann Rheum Dis 2013;72:204-10.

51. Palmowski Y, Buttgereit T, Dejaco C, Bijlsma JW, Matteson EL, Voshaar M, et al. "Official View" on Glucocorticoids in Rheumatoid Arthritis: A Systematic Review of International Guidelines and Consensus Statements. Arthritis Care Res (Hoboken) 2017;69:1134-41.
52. Buttgereit F, Strand V, Lee EB, McCabe D, Kolluri S, Tammara B. Efficacy and safety of PF-04171327, a novel dissociated agonist of the glucocorticoid receptor (DAGR): Results of a phase 2, randomized, double-blind study. Ann Rheum Dis. 2015;74:737-38.

53. To evaluate the efficacy and safety of sunpharma 1505 compared with reference 1505 in subjects with active rheumatoid arthritis. Available from: https:// clinicaltrials.gov/ct2/show/NCT02534896. [Access date: February 10. 2018]

54. Smolen JS, Van Der Heijde DM, St Clair EW, Emery $\mathrm{P}$, Bathon JM, Keystone E, et al. Predictors of joint damage in patients with early rheumatoid arthritis treated with high-dose methotrexate with or without concomitant infliximab: Results from the ASPIRE trial. Arthritis Rheum 2006;54:702-10

55. van der Heijde DM, van Riel PL, van Leeuwen MA, van 't Hof MA, van Rijswijk MH, van de Putte LB. Prognostic factors for radiographic damage and physical disability in early rheumatoid arthritis. A prospective follow-up study of 147 patients. $\mathrm{Br} \mathrm{J}$ Rheumatol 1992;31:519-25.

56. van Leeuwen MA, van Rijswijk MH, Sluiter WJ, van Riel PL, Kuper IH, van de Putte LB, et al. Individual relationship between progression of radiological damage and the acute phase response in early rheumatoid arthritis. Towards development of a decision support system. J Rheumatol 1997;24:20-7.

57. Saevarsdottir S, Rezaei H, Geborek P, Petersson I, Ernestam S, Albertsson K, et al. Current smoking status is a strong predictor of radiographic progression in early rheumatoid arthritis: Results from the SWEFOT trial. Ann Rheum Dis 2015;74:1509-14.

58. Naredo E, Collado P, Cruz A, Palop MJ, Cabero F, Richi $\mathrm{P}$, et al. Longitudinal power Doppler ultrasonographic assessment of joint inflammatory activity in early rheumatoid arthritis: predictive value in disease activity and radiologic progression. Arthritis Rheum 2007;57:116-24.

59. Sreerangaiah D, Grayer M, Fisher BA, Ho M, Abraham S, Taylor PC. Quantitative power Doppler ultrasound measures of peripheral joint synovitis in poor prognosis early rheumatoid arthritis predict radiographic progression. Rheumatology (Oxford) 2016;55:89-93.

60. Hetland ML, Ejbjerg B, Hørslev-Petersen K, Jacobsen $\mathrm{S}$, Vestergaard A, Jurik AG, et al. MRI bone oedema is the strongest predictor of subsequent radiographic progression in early rheumatoid arthritis. Results from a 2-year randomised controlled trial (CIMESTRA). Ann Rheum Dis 2009;68:384-90.

61. Haavardsholm EA, Bøyesen P, Østergaard M, Schildvold A, Kvien TK. Magnetic resonance imaging findings in 84 patients with early rheumatoid arthritis: bone marrow oedema predicts erosive progression. Ann Rheum Dis 2008;67:794-800. 
62. McQueen FM, Benton N, Perry D, Crabbe J, Robinson E, Yeoman S, et al. Bone edema scored on magnetic resonance imaging scans of the dominant carpus at presentation predicts radiographic joint damage of the hands and feet six years later in patients with rheumatoid arthritis. Arthritis Rheum 2003;48:1814-27.

63. Sauer BC, Teng CC, Tang D, Leng J, Curtis JR, Mikuls TR, et al. Persistence with conventional triple therapy versus a tumor necrosis factor inhibitor and methotrexate in US veterans with rheumatoid arthritis. Arthritis Care Res (Hoboken) 2017;69:313-22

64. O'Dell JR, Mikuls TR, Taylor TH, Ahluwalia V, Brophy M, Warren SR, et al. Therapies for active rheumatoid arthritis after methotrexate failure. $\mathrm{N} \mathrm{Engl}$ J Med 2013;369:307-18.

65. Peper SM, Lew R, Mikuls T, Brophy M, Rybin $\mathrm{D}$, Wu $\mathrm{H}$, et al. Rheumatoid arthritis treatment after methotrexate: the durability of triple therapy versus etanercept. Arthritis Care Res (Hoboken) 2017;69:1467-72.

66. Hazlewood GS, Barnabe C, Tomlinson G, Marshall D, Devoe DJ, Bombardier C. Methotrexate monotherapy and methotrexate combination therapy with traditional and biologic disease modifying anti-rheumatic drugs for rheumatoid arthritis: A network meta-analysis. Cochrane Database Syst Rev 2016;8:CD010227.

67. Mary J, De Bandt M, Lukas C, Morel J, Combe $\mathrm{B}$. Triple oral therapy versus antitumor necrosis factor plus methotrexate (MTX) in patients with rheumatoid arthritis and nadequate response to MTX: a systematic literature review. J Rheumatol 2017;44:773-9.

68. Fleischmann $\mathrm{R}$, van Vollenhoven RF, Vencovsky $\mathrm{J}$, Alten R, Davies O, Mountian I, et al. Longterm maintenance of certolizumab pegol safety and efficacy, in combination with methotrexate and as monotherapy, in rheumatoid arthritis patients. Rheumatol Ther 2017;4:57-69.

69. Westhovens R, Kremer JM, Emery P, Russell AS, Alten R, Barré E, et al. Long-term safety and efficacy of abatacept in patients with rheumatoid arthritis and an inadequate response to methotrexate: a 7-year extended study. Clin Exp Rheumatol 2014;32:553-62.

70. Bergrath E, Gerber RA, Gruben D, Lukic T, Makin C, Wallenstein G. Tofacitinib versus biologic treatments in moderate-to-severe rheumatoid arthritis patients who have had an inadequate response to nonbiologic DMARDs: systematic literature review and network meta-analysis. Int $\mathrm{J}$ Rheumatol 2017;2017:8417249.

71. Charles-Schoeman C, Burmester G, Nash P, Zerbini CA, Soma K, Kwok K, et al. Efficacy and safety of tofacitinib following inadequate response to conventional synthetic or biological disease-modifying antirheumatic drugs. Ann Rheum Dis 2016;75:1293-301.
72. Rheumatoid arthritis in adults: Management, clinical guideline. National institute for health and care excellence. Tofacitinib for moderate to severe rheumatoid arthritis. Technology appraisal guidance [TA480] Published date: 11 October 2017. Available from: https://www.nice.org.uk/guidance/ ta480/chapter/1-Recommendations. [Access date: February 10, 2018]

73. Taylor PC, Keystone EC, van der Heijde D, Weinblatt ME, Del Carmen Morales L, Reyes Gonzaga J, et al. Baricitinib versus placebo or adalimumab in rheumatoid arthritis. N Engl J Med 2017;376:652-62.

74. Porter D, van Melckebeke J, Dale J, Messow CM, McConnachie A, Walker A, et al. Tumour necrosis factor inhibition versus rituximab for patients with rheumatoid arthritis who require biological treatment (ORBIT): an open-label, randomised controlled, noninferiority, trial. Lancet 2016;388:239-47.

75. Wijesinghe H, Galappatthy P, de Silva R, Seneviratne SL, Saravanamuttu U, Udagama P, et al. Leflunomide is equally efficacious and safe compared to low dose rituximab in refractory rheumatoid arthritis given in combination with methotrexate: results from a randomized double blind controlled clinical trial. BMC Musculoskelet Disord 2017;18:310.

76. Tanaka Y,HirataS, SaleemB, EmeryP. Discontinuation of biologics in patients with rheumatoid arthritis. Clin Exp Rheumatol 2013;31(4 Suppl 78):S22-7.

77. Bejarano V, Conaghan PG, Quinn MA, Saleem $\mathrm{B}$, Emery $\mathrm{P}$. Benefits 8 years after a remission induction regime with an infliximab and methotrexate combination in early rheumatoid arthritis. Rheumatology (Oxford) 2010;49:1971-4.

78. van der Kooij SM, le Cessie S, Goekoop-Ruiterman YP, de Vries-Bouwstra JK, van Zeben D, Kerstens $\mathrm{PJ}$, et al. Clinical and radiological efficacy of initial vs delayed treatment with infliximab plus methotrexate in patients with early rheumatoid arthritis. Ann Rheum Dis 2009;68:1153-8.

79. Detert J, Bastian H, Listing J, Weiß A, Wassenberg $\mathrm{S}$, Liebhaber $\mathrm{A}$, et al. Induction therapy with adalimumab plus methotrexate for 24 weeks followed by methotrexate monotherapy up to week 48 versus methotrexate therapy alone for DMARDnaive patients with early rheumatoid arthritis: HIT HARD, an investigator-initiated study. Ann Rheum Dis 2013;72:844-50.

80. Bijlsma JWJ, Welsing PMJ, Woodworth TG, Middelink LM, Pethö-Schramm A, Bernasconi C, et al. Early rheumatoid arthritis treated with tocilizumab, methotrexate, or their combination (U-Act-Early): a multicentre, randomised, double-blind, doubledummy, strategy trial. Lancet 2016;388:343-55.

81. Atsumi T, Yamamoto K, Takeuchi T, Yamanaka $\mathrm{H}$, Ishiguro $\mathrm{N}$, Tanaka $\mathrm{Y}$, et al. The first doubleblind, randomised, parallel-group certolizumab pegol study in methotrexate-naive early rheumatoid arthritis patients with poor prognostic factors, C-OPERA, 
shows inhibition of radiographic progression. Ann Rheum Dis 2016;75:75-83.

82. Kavanaugh A, van Vollenhoven RF, Fleischmann R, Emery P, Sainsbury I, Florentinus S, et al. Testing treat-to-target outcomes with initial methotrexate monotherapy compared with initial tumour necrosis factor inhibitor (adalimumab) plus methotrexate in early rheumatoid arthritis. Ann Rheum Dis 2018;77:289-92.

83. Jalal H, O'Dell JR, Bridges SL Jr, Cofield S, Curtis JR, Mikuls TR, et al. Cost-Effectiveness of triple therapy versus etanercept plus methotrexate in early aggressive rheumatoid arthritis. Arthritis Care Res (Hoboken) 2016;68:1751-7.

84. Jones G, Wallace T, McIntosh MJ, Brockwell L, Gómez-Reino JJ, Sebba A. Five-year efficacy and safety of tocilizumab monotherapy in patients with rheumatoid arthritis who were methotrexate- and biologic-naive or free of methotrexate for 6 months: the AMBITION Study. J Rheumatol 2017;44:142-6.

85. Burmester GR, Rigby WF, van Vollenhoven RF, Kay J, Rubbert-Roth A, Blanco R, et al. Tocilizumab combination therapy or monotherapy or methotrexate monotherapy in methotrexatenaive patients with early rheumatoid arthritis: 2-year clinical and radiographic results from the randomised, placebo-controlled FUNCTION trial. Ann Rheum Dis 2017;76:1279-84.

86. Dougados M, Kissel K, Conaghan PG, Mola EM, Schett G, Gerli R, et al. Clinical, radiographic and immunogenic effects after 1 year of tocilizumabbased treatment strategies in rheumatoid arthritis: the ACT-RAY study. Ann Rheum Dis 2014;73:803-9.

87. Fleischmann R, Kremer J, Cush J, Schulze-Koops H, Connell CA, Bradley JD, et al. Placebo-controlled trial of tofacitinib monotherapy in rheumatoid arthritis. N Engl J Med 2012;367:495-507.

88. Fleischmann RM, Huizinga TW, Kavanaugh AF, Wilkinson B, Kwok K, DeMasi R, et al. Efficacy of tofacitinib monotherapy in methotrexate-naive patients with early or established rheumatoid arthritis. RMD Open 2016;2:e000262.

89. Fleischmann R, Mysler E, Hall S, Kivitz AJ, Moots RJ, Luo Z, et al. Efficacy and safety of tofacitinib monotherapy, tofacitinib with methotrexate, and adalimumab with methotrexate in patients with rheumatoid arthritis (ORAL Strategy): a phase $3 \mathrm{~b} / 4$, double-blind, head-to-head, randomised controlled trial. Lancet 2017;390:457-68.

90. Claxton L, Jenks M, Taylor M, Wallenstein G, Mendelsohn AM, Bourret JA, et al. An economic evaluation of tofacitinib treatment in rheumatoid arthritis: modeling the cost of treatment strategies in the United States. J Manag Care Spec Pharm 2016;22:1088-102.

91. van Riel PL, Taggart AJ, Sany J, Gaubitz M, Nab HW, Pedersen R, et al. Efficacy and safety of combination etanercept and methotrexate versus etanercept alone in patients with rheumatoid arthritis with an inadequate response to methotrexate: the ADORE study. Ann Rheum Dis 2006;65:1478-83.

92. Tarp S, Furst DE, Dossing A, Ostergaard M, Lorenzen T, Hansen MS, et al. Defining the optimal biological monotherapy in rheumatoid arthritis: A systematic review and meta-analysis of randomised trials. Semin Arthritis Rheum 2017;46:699-708.

93. Gaubitz M, Göttl KH, Behmer O, Lippe R, Meng $\mathrm{T}$, Löschmann PA. Etanercept is effective as monotherapy or in combination with methotrexate in rheumatoid arthritis: subanalysis of an observational study. Clin Rheumatol. 2017;36:1989-96.

94. NICE. Adalimumab, etanercept, infliximab, certolizumab pegol, golimumab, tocilizumab and abatacept for rheumatoid arthritis not previously treated with DMARDs or after conventional DMARDs only have failed. London (UK): National Institute for Health and Care Excellence (NICE). Technology Appraisal Guidance; No. 375. 2016. Available from: https://www.nice.org.uk/guidance/ta375. [Access date: February 10, 2018]

95. Gottenberg JE, Brocq O, Perdriger A, Lassoued $\mathrm{S}$, Berthelot JM, Wendling $\mathrm{D}$, et al. Non-TNFtargeted biologic vs a second anti-TNF drug to treat rheumatoid arthritis in patients with insufficient response to a first anti-TNF drug: A Randomized Clinical Trial. JAMA 2016;316:1172-80.

96. Bessette L, Khraishi M, Kivitz AJ, Kaliyaperumal A, Grantab R, Poulin-Costello M, et al. Single-arm study of etanercept in adult patients with moderate to severe rheumatoid arthritis who failed adalimumab treatment. Rheumatol Ther 2017;4:391-404.

97. Rheumatoid arthritis in adults: Management, clinical guideline. National institute for health and care excellence. Adalimumab, etanercept, infliximab, rituximab and abatacept for the treatment of rheumatoid arthritis after the failure of a TNF inhibitor. Technology Appraisal Guidance [TA195] [Published date: August 25, 2010]. Available from: https://www.nice.org.uk/guidance/ta195/chapter/1Guidance [Access date: February 10, 2018]

98. Wei W, Knapp K, Wang L, Chen CI, Craig GL, Ferguson K, et al. Treatment persistence and clinical outcomes of tumor necrosis factor 1nhibitor cycling or switching to a new mechanism of action therapy: real-world observational study of rheumatoid arthritis patients in the united states with prior tumor necrosis factor nhibitor therapy. Adv Ther 2017;34:1936-52.

99. Yoo DH, Racewicz A, Brzezicki J, Yatsyshyn R, Arteaga ET, Baranauskaite A, et al. A phase III randomized study to evaluate the efficacy and safety of CT-P13 compared with reference infliximab in patients with active rheumatoid arthritis: 54-week results from the PLANETRA study. Arthritis Res Ther 2016;18:82.

100. Smolen JS, Cohen SB, Tony HP, Scheinberg M, Kivitz A, Balanescu A, et al. A randomised, double-blind 
trial to demonstrate bioequivalence of gp2013 and reference rituximab combined with methotrexate in patients with active rheumatoid arthritis. Ann Rheum Dis 2017;76:1598-602.

101. Jamshidi A, Gharibdoost F, Vojdanian M, Soroosh SG, Soroush M, Ahmadzadeh A, et al. A phase III, randomized, two-armed, double-blind, parallel, active controlled, and non-inferiority clinical trial to compare efficacy and safety of biosimilar adalimumab $\left(\right.$ CinnoRA $\left.^{\circledR}\right)$ to the reference product $\left(\right.$ Humira $\left.^{\circledR}\right)$ in patients with active rheumatoid arthritis. Arthritis Res Ther 2017;19:168.

102. Brodszky V, Baji P, Balogh O, Péntek M. Budget impact analysis of biosimilar infliximab (CT-P13) for the treatment of rheumatoid arthritis in six Central and Eastern European countries. Eur J Health Econ 2014;15 Suppl 1:S65-71.

103. Ruiz-Argüello MB, Maguregui A, Ruiz Del Agua A, Pascual-Salcedo D, Martínez-Feito A, Jurado T, et al. Antibodies to infliximab in Remicade-treated rheumatic patients show identical reactivity towards biosimilars. Ann Rheum Dis 2016;75:1693-6.

104. Hamann P, Holland R, Hyrich K, Pauling JD, Shaddick G, Nightingale A, et al. Factors associated with sustained remission in rheumatoid arthritis in patients treated with anti-tumor necrosis factor. Arthritis Care Res (Hoboken) 2017;69:783-93.

105. Emery P, Hammoudeh M, FitzGerald O, Combe B, Martin-Mola E, Buch $\mathrm{MH}$, et al. Sustained remission with etanercept tapering in early rheumatoid arthritis. N Engl J Med 2014;371:1781-92.

106. Smolen JS, Nash P, Durez P, Hall S, Ilivanova $\mathrm{E}$, Irazoque-Palazuelos $\mathrm{F}$, et al. Maintenance, reduction, or withdrawal of etanercept after treatment with etanercept and methotrexate in patients with moderate rheumatoid arthritis (PRESERVE): a randomised controlled trial. Lancet 2013;381:918-29.

107. Yasuda S, Ohmura K, Kanazawa H, Kurita T, Kon Y, Ishii $\mathrm{T}$, et al. Maintenance treatment using abatacept with dose reduction after achievement of low disease activity in patients with rheumatoid arthritis (matador) - a prospective, multicenter, single arm pilot clinical trial. Mod Rheumatol 2017;27:930-7.

108. Henaux S, Ruyssen-Witrand A, Cantagrel A, Barnetche T, Fautrel B, Filippi N, et al. Risk of losing remission, low disease activity or radiographic progression in case of bDMARD discontinuation or tapering in rheumatoid arthritis: systematic analysis of the literature and meta-analysis. Ann Rheum Dis 2018;77:515-22.

109. Lau CS, Gibofsky A, Damjanov N, Lula S, Marshall $\mathrm{L}$, Jones $\mathrm{H}$, et al. Down-titration of biologics for the treatment of rheumatoid arthritis: a systematic literature review. Rheumatol Int 2017;37:1789-98.

110. Schett G, Emery P, Tanaka Y, Burmester G, Pisetsky DS, Naredo E, et al. Tapering biologic and conventional dmard therapy in rheumatoid arthritis: Current evidence and future directions. Ann Rheum Dis 2016;75:1428-37.

111. Naredo E, Valor L, De la Torre I, Montoro M, Bello N, Martinez-Barrio J, et al. Predictive value of doppler ultrasound-detected synovitis in relation to failed tapering of biologic therapy in patients with rheumatoid arthritis. Rheumatology (Oxford) 2015;54:1408-14.

112. Scott IC, Kingsley GH, Scott DL. Can we discontinue synthetic disease-modifying anti-rheumatic drugs in rheumatoid arthritis? Clin Exp Rheumatol 2013;31(4 Suppl 78):S4-8.

113. van der Woude D, Young A, Jayakumar K, Mertens BJ, Toes RE, van der Heijde D, et al. Prevalence of and predictive factors for sustained disease-modifying antirheumatic drug-free remission in rheumatoid arthritis: Results from two large early arthritis cohorts. Arthritis Rheum 2009;60:2262-71.

114. O'Mahony R, Richards A, Deighton C, Scott D. Withdrawal of disease-modifying antirheumatic drugs in patients with rheumatoid arthritis: A systematic review and meta-analysis. Ann Rheum Dis 2010;69:1823-6.

115. Brown AK, Quinn MA, Karim Z, Conaghan PG, Peterfy CG, Hensor E, et al. Presence of significant synovitis in rheumatoid arthritis patients with disease-modifying antirheumatic drug-induced clinical remission: evidence from an imaging study may explain structural progression. Arthritis Rheum 2006;54:3761-73.

116. Cohen G, Gossec L, Dougados M, Cantagrel A, Goupille P, Daures JP, et al. Radiological damage in patients with rheumatoid arthritis on sustained remission. Ann Rheum Dis 2007;66:358-63. 